\title{
An Overview of the Molecular Mechanisms of Recombinational DNA Repair
}

\author{
Stephen C. Kowalczykowski \\ Department of Microbiology \& Molecular Genetics and Department of Molecular and Cellular Biology, \\ University of California, Davis, Davis, California 95616 \\ Correspondence: sckowalczykowski@ucdavis.edu
}

\begin{abstract}
Recombinational DNA repair is a universal aspect of DNA metabolism and is essential for genomic integrity. It is a template-directed process that uses a second chromosomal copy (sister, daughter, or homolog) to ensure proper repair of broken chromosomes. The key steps of recombination are conserved from phage through human, and an overview of those steps is provided in this review. The first step is resection by helicases and nucleases to produce single-stranded DNA (ssDNA) that defines the homologous locus. The ssDNA is a scaffold for assembly of the RecA/RAD51 filament, which promotes the homology search. On finding homology, the nucleoprotein filament catalyzes exchange of DNA strands to form a joint molecule. Recombination is controlled by regulating the fate of both RecA/RAD51 filaments and DNA pairing intermediates. Finally, intermediates that mature into Holliday structures are disjoined by either nucleolytic resolution or topological dissolution.
\end{abstract}

$\mathrm{T}_{\mathrm{r} \text { te }}^{\mathrm{h}}$ he study and appreciation of homologous recombination has emerged from a diverse set of sources and disciplines. Historically, recombination was studied as an essential part and consequence of the meiotic process: both cytology of plant and animal cells, and genetic analyses of fungi including yeasts were used to understand the nature of crossing-over of genes and whole chromosomes (see Subramanian and Hochwagen 2014; Brown and Bishop 2015; Herbert et al. 2015; Hunter 2015; Lam and Keeney 2015; Zickler and Kleckner 2015). In parallel, work in bacteria established recombination as an essential part of conjugation and natural genetic transformation (Clark and Margulies 1965; Clark 1973), and in bacterial evolution and survival strategies (Reams and Roth
2015). However, it was the work in phages that began a string of connections that would ultimately lead to an appreciation of recombination as an integral part of chromosomal replication. Now, the role of homologous recombination in genome maintenance in all organisms is fully appreciated. Studies in bacteriophage T4 showed that recombination was important to DNA replication by providing a DNA “primer" to permit extensive and rapid chromosomal synthesis: an early example of "break-induced" replication (Doermann et al. 1955; Mosig 1987). This paradigm for recombination-dependent replication was then discovered to be essential for complete chromosome synthesis in the bacterium, Escherichia coli, establishing the iconoclastic view that replication of the bacte-

Editors: Stephen Kowalczykowski, Neil Hunter, and Wolf-Dietrich Heyer

Additional Perspectives on DNA Recombination available at www.cshperspectives.org

Copyright (C) 2015 Cold Spring Harbor Laboratory Press; all rights reserved; doi: 10.1101/cshperspect.a016410

Cite this article as Cold Spring Harb Perspect Biol 2015;7:a016410 
rial chromosome was rarely completed, uninterrupted, from a bacterial origin to the terminus and that it required recombination to restore replication (Asai et al. 1994; Kogoma 1997; Syeda et al. 2014). In short order thereafter, the general concept that homologous recombination was part of a broader aspect of DNA metabolism, a process that not only repairs DNA with breaks, either single-stranded or doublestranded, but one that also intersects and overlaps with transcription (Aguilera and Gaillard 2014) and mismatch repair (Spies and Fishel 2015), and is affected by and affects chromosome structure (Székvölgyi et al. 2015). Recombination-dependent repair or replication is a template-directed repair process that takes advantage of a sister (or daughter) or homologous chromosome to ensure the relatively accurate repair of the break with accompanied DNA synthesis or replication (Mehta and Haber 2014; Heyer 2015). The homologs and analogs of these phage and bacterial proteins were subsequently uncovered in eukaryotes, initially in Saccharomyces cerevisiae and then in other sequenced genomes, verifying the ubiquity of this conserved genome maintenance system (Schiller et al. 2014; Symington 2014; Lisby and Rothstein 2015; Morrical 2015). Because of this rich legacy, we can now conceptually understand how mutations in human genes, such as $B R C A 1, B R C A 2$, and BLM, as well as a score of FANC genes (whose mutation causes Fanconi anemia), give rise to a high predisposition to cancer because of the essential role of these proteins (and many others) in chromosome and telomere maintenance via recombinational DNA repair (Bizard and Hickson 2014; Daley et al. 2014b; Doksani and de Lange 2014; Wyatt and West 2014; Zelensky et al. 2014; Prakash et al. 2015). The failure to repair chromosomes leads to a genetic instability that gives rise to uncontrolled cell growth characteristic of tumor cells (Hoeijmakers 2001; Deans and West 2011).

\section{CAUSES OF DNA BREAKS AND PATHWAYS OF RECOMBINATIONAL DNA REPAIR}

DNA damage is an inescapable consequence of chemistry: DNA bases and sugars can be mod- ified or mispaired, and chain continuity can be broken. Some of these forms of DNA damage are handled by base excision repair, nucleotide excision repair, and mismatch DNA repair systems. This review will not discuss those repair systems, but rather focus only on how DNA strand breaks are repaired by homologous recombination.

DNA strand breaks can occur directly, as the result of chemistry, or indirectly, as the result of DNA replication on a damaged template or collision with the transcription machinery (Aguilera and Gaillard 2014; Mehta and Haber 2014; Syeda et al. 2014). Both single-stranded DNA gaps (SSGs) and double-stranded DNA breaks (DSBs) are created every cell cycle as a consequence of DNA replication through imperfect DNA (Kowalczykowski 2000). At first blush, one could imagine that repair of these strand discontinuities could occur by fill-in DNA synthesis or ligation. But this is not possible if the lesion cannot be replicated (e.g., an interstrand crosslink), is too slow to repair or replicate (Lange et al. 2011), or creates a singleended DSB (e.g., replication through a nicked template). Similarly, when both ends of a single DSB are present, they can be rejoined unambiguously by nonhomologous end-joining (NHEJ); however, if more than one DSB is present in the chromosome, then the wrong ends can be rejoined, resulting in random translocations. Although NHEJ is a cellular alternative to homologous recombination for repairing DSBs, because repair via recombination is a templatedirected process, the homologous alignment step with a sister or homologous chromosome ensures a high probability of joining the correct ends.

Homologous recombination does not comprise a single simple mechanism that applies to all breaks, in all organisms, at all times. This is because of the diversity and size of SSGs and DSBs, their origin, the timing of the cell cycle, and the cell type (Mehta and Haber 2014). Consequently, recombination mechanisms do not comprise a straightforward linear process, such as replication or transcription, but rather a collection of potentially parallel and alternative processes (Heyer 2015). An appreciation of 
An Overview of Recombination

the complexity of the many molecular steps and their alternatives are provided in this compilation.

However disparate these mechanisms of recombinational repair might appear, they consist of several core biochemical steps that will be summarized here. Recombinational DNA repair comprises several universal biochemical steps (Fig. 1): "initiation," which is resection or enlargement of the DNA break by nucleases and DNA helicases to create single-stranded DNA (ssDNA); "homologous DNA pairing and strand exchange," which involves the search for sequence complementarity promoted by the ubiquitous RecA/RAD51 nucleoprotein filament (note that a slash [/] between protein names signifies that they behave analogously, and the comment applies to each) and the reciprocal exchange of DNA strands; "branch migration" of three- or four-stranded intermediates, where a joint molecule, single Holliday junction $(\mathrm{HJ})$, or double Holliday junction $(\mathrm{dHJ})$ is migrated to either extend heteroduplex DNA or disrupted to unpair the DNA through the action of a DNA motor protein and possibly a topoisomerase; and finally, separation of the joined chromosomes by nucleolytic resolution or by topological dissolution involving a type IA topoisomerase and DNA helicase. These core steps are conserved in most Phage, Bacteria, Archaea, and Eukarya (Kuzminov 1999; Kreuzer 2000; Seitz et al. 2001; Heyer et al. 2010). Although the work in phages, particularly T4 and lambda, is classic, space constraints prohibit a detailed discussion; rather, the reader is directed to the reviews where a more extensive comparison of the DNA strand exchange proteins and their mediators includes T4 UvsX and UvsY (Zelensky et al. 2014; Morrical 2015), the DNA resection and annealing proteins of phage $\lambda, \operatorname{Red} \alpha$ and $\operatorname{Red} \beta$ (Morrical 2015), and the phage resolution enzymes (Wyatt and West 2014). Similarly, the Archaea will not be summarized herein; the interested reader is referred to literature on the Archaeal orthologs of the resection machinery (Symington 2014), the mediators (Zelensky et al. 2014), and resolution enzymes (Wyatt and West 2014).

\section{Bacteria}

In many bacteria, there are two major pathways for recombinational DNA repair: the RecBCD/ AddAB pathway and the RecF pathway (Kowalczykowski et al. 1994). In E. coli, the RecBCD pathway is responsible for the repair of DSBs (Dillingham and Kowalczykowski 2008; Yeeles and Dillingham 2010), whereas the RecF pathway is largely responsible for repairs of SSGs (Table 1) (Spies and Kowalczykowski 2005). Genetic and genomic analyses show that the RecF pathway is nearly universal among the bacteria (Rocha et al. 2005). In other bacteria, such as Bacillus subtilis, both the AddAB and RecF pathways operate on DSBs and only the RecF pathway repairs SSGs, rationalizing the more common conservation of RecF pathway components (Rocha et al. 2005). Although recombinational repair is segregated in wild-type E. coli, two mutations $(s b c B$ and $s b c C D$ ) that alter two nucleases (attenuation of Exonuclease I and inactivation of SbcCD) allow the RecF pathway to act on DSBs (Kowalczykowski et al. 1994; Kuzminov 1999), showing that the enzymes of this pathway have the capacity to act on DSBs. Interestingly, an alternate means to activate DSB resection by $\mathrm{RecF}$ pathway components is to eliminate the genes ( $x o n$ and $x s e$ ) for exonuclease I and exonuclease VII from E. coli (Viswanathan et al. 2000); these nucleases are not present in wild-type B. subtilis, explaining why the RecF system can act constitutively on DSBs. These nucleases degrade ssDNA from its $3^{\prime}$-end, revealing that preservation of the $3^{\prime}$-ended ssDNA intermediate at a resected DNA end is essential for repair by recombination, and also revealing biochemical conformity with the eukaryotic pathways discussed below.

\section{Yeast}

In $S$. cerevisiae, recombinational DNA repair is mediated by the so-called RAD52-epistatis group, and their ancillary components. The group includes Rad50, Rad51, Rad52, Rad54, Rad55, Rad57, Rad59, Mre11 (Rad58), Xrs2, Mus81, Mms4, Sgs1, Top3, Rmi1, Dna2, exonuclease 1 (Exo1), and replication protein-A 


\section{S.C. Kowalczykowski}
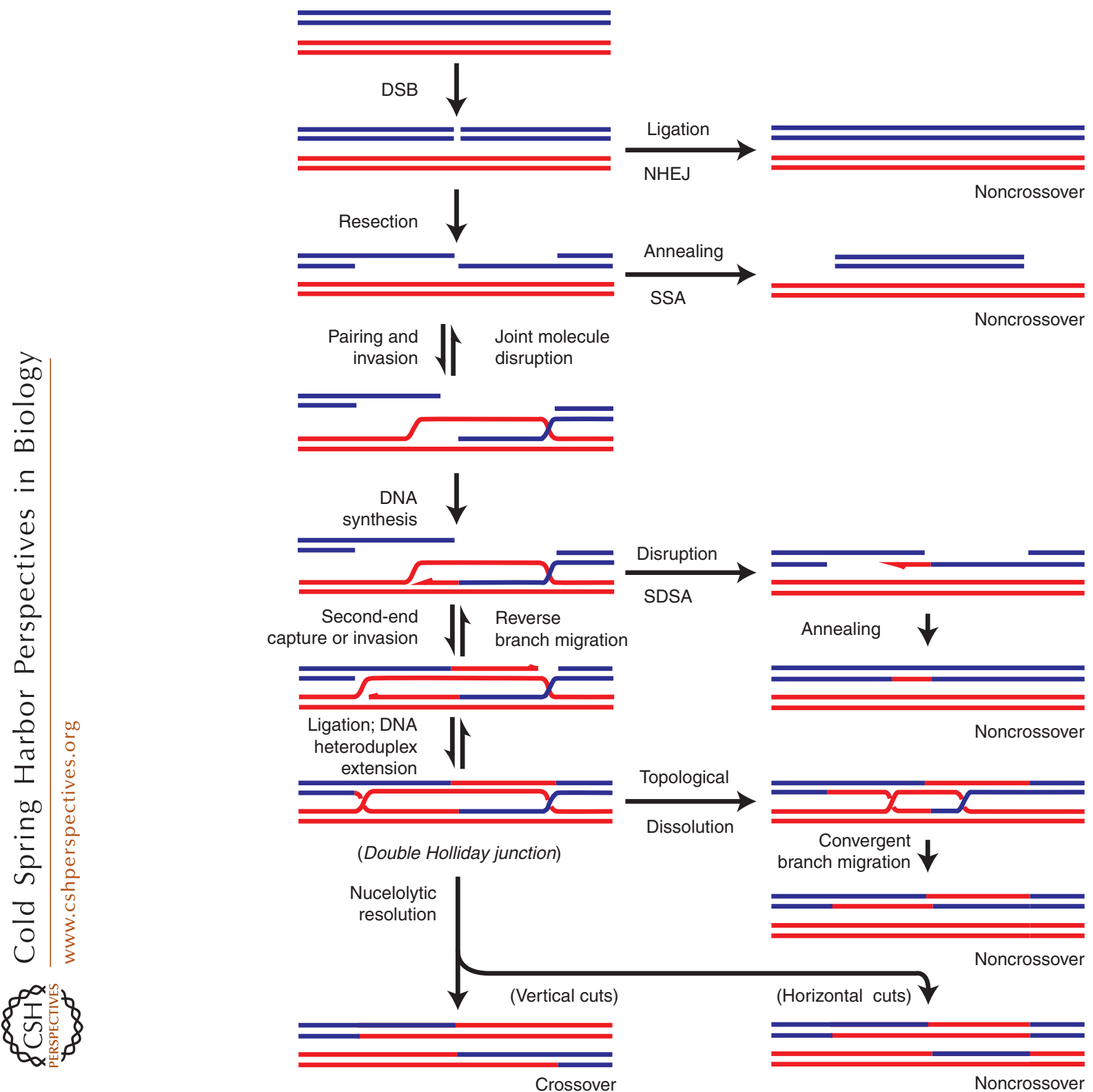

Figure 1. Molecular mechanism of recombinational DNA repair. The steps comprising recombinational DNA repair are schematically illustrated (see text for details). Some steps are unidirectional commitments (e.g., resection) and are shown with single arrows, whereas others are reversible (e.g., DNA pairing and invasion), and are shown with two arrows. In the latter case, the forward step is shown to the left of the arrows, and the backward step is shown to the right. Intermediates from the biochemical steps are channeled into the repair pathways shown. DSB, double-stranded DNA break; NHEJ, nonhomologous end joining; SSA, single-strand DNA annealing; SDSA, synthesis-dependent strand annealing. The outcome of each pathway, crossover or noncrossover, is indicated. (From Cejka et al. 2010b; adapted, with permission, from the authors.) 
Table 1. Proteins involved in recombinational DNA repair

\begin{tabular}{|c|c|c|c|}
\hline & E. coli & S. cerevisiae & Human \\
\hline $\begin{array}{l}\text { Initiation } \\
\quad(\text { resection })\end{array}$ & $\begin{array}{c}\text { RecBCD } \\
\text { SbcCD, RecN } \\
\text { RecQ } \\
\text { RecJ } \\
-\end{array}$ & $\begin{array}{c}\text { Sgs1-Dna2 } \\
\text { Mre11-Rad50-Xrs2-Sae2 } \\
\text { Sgs1 } \\
\text { Exo1 } \\
\text { Fun30, Ino80, Rsc }\end{array}$ & $\begin{array}{c}\text { BLM-DNA2 } \\
\text { MRE11-RAD50-NBS1-CtIP } \\
\text { BLM/WRN } \\
\text { EXO1 } \\
\text { SMARCAD1, INO80, RSC }\end{array}$ \\
\hline $\begin{array}{l}\text { Homologous } \\
\text { DNA pairing }\end{array}$ & $\operatorname{RecA}$ & Rad51 & RAD51 \\
\hline $\begin{array}{l}\text { Mediators and } \\
\text { positive } \\
\text { regulators of } \\
\text { RecA/RAD51 } \\
\text { filaments }\end{array}$ & $\begin{array}{c}\text { SSB } \\
\text { RecFOR } \\
- \\
\text { RecO } \\
\text { DinI }^{\mathrm{c}} \\
- \\
-\end{array}$ & $\begin{array}{c}\text { RPA } \\
\text { Rad55-Rad57 } \\
\text { Shu1/Shu2/Psy3/Csm2 } \\
\text { Rad52/Rad59 } \\
- \\
\text { Rad54/Rdh54 } \\
-\end{array}$ & 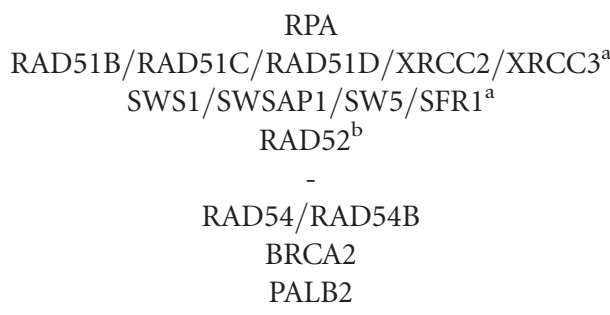 \\
\hline $\begin{array}{l}\text { Negative } \\
\text { regulators/ } \\
\text { filament } \\
\text { disruption }\end{array}$ & $\begin{array}{l}\text { SSB } \\
\text { UvrD } \\
\operatorname{RecX}\end{array}$ & $\begin{array}{l}\text { RPA } \\
\text { Srs2 } \\
-\end{array}$ & $\begin{array}{c}\text { RPA } \\
\text { FBH1 } \\
\text { PARI } \\
\text { FANCJ } \\
\text { BLM/RECQ5 }\end{array}$ \\
\hline $\begin{array}{l}\text { Joint molecule } \\
\text { disruption }\end{array}$ & $\begin{array}{c}\text { RecQ } \\
\text { UvrD } \\
- \\
- \\
\text { RecG } \\
\left(\text { TopoIII }{ }^{\mathrm{e}}\right)\end{array}$ & $\begin{array}{c}\text { Sgs1 } \\
\text { Srs2 } \\
\text { Rad54/Rdh54 } \\
\text { Mph1 } \\
- \\
\text { Top3 }\end{array}$ & $\begin{array}{c}\mathrm{BLM}^{\mathrm{d}} / \mathrm{RECQ}^{\mathrm{d}} / \mathrm{WRN}^{\mathrm{d}} /\left(\mathrm{RECQ}^{\mathrm{e}} / \mathrm{RECQ}^{\mathrm{e}}\right) \\
\left(\mathrm{FBH}^{\mathrm{e}}\right) \\
\text { RAD } 54 /\left(\mathrm{RAD}^{\mathrm{e}} 4 \mathrm{~B}^{\mathrm{e}}\right) \\
\left(\mathrm{FANCM}^{\mathrm{e}}\right) \\
\text { SMARCAL1 } / \text { ZRANB }^{\mathrm{e}} \\
\left(\text { TOPOIII }^{\mathrm{e}}\right)\end{array}$ \\
\hline $\begin{array}{l}\text { DNA heteroduplex } \\
\text { extension } \\
\text { (three- and } \\
\text { four-stranded) }\end{array}$ & $\begin{array}{l}\text { RuvAB } \\
\text { RecG } \\
\text { RecQ } \\
\text { UvrD }\end{array}$ & $\begin{array}{c}\text { Rad54/Rdh54 } \\
- \\
\text { Sgs1 } \\
\text { Srs2 } \\
\text { Mph1 }\end{array}$ & $\begin{array}{c}\left.\text { RAD54/(RAD54B }{ }^{\mathrm{e}}\right) \\
\text { SMACAL1/ZRANB } \\
\text { BLM/RECQ1/WRN } /\left(\text { RECQ4 }^{\mathrm{e}} / \text { RECQ5 }^{\mathrm{e}}\right) \\
\left(\mathrm{FBH} 1^{\mathrm{e}}\right) \\
\text { FANCM }\end{array}$ \\
\hline Resolution & $\begin{array}{c}\text { RuvC } \\
- \\
-\end{array}$ & $\begin{array}{c}\text { Yen } 1 \\
\text { Mus81-Mms4 } \\
\text { Slx1-Slx4 }\end{array}$ & $\begin{array}{c}\text { GEN1 } \\
\text { MUS81-EME1, MUS81-EME2 } \\
\text { SLX1-SLX4/BTBD12 }\end{array}$ \\
\hline
\end{tabular}

$\begin{array}{lll}\text { Dissolution } & \text { RecQ-TopoIII Sgs1-Top3-Rmil BLM-TOPOIII } \alpha-R M I 1-R M I 2\end{array}$

Proteins are listed for E. coli, S. cerevisiae, and Homo sapiens. Each major horizontal section describes the step in recombinational repair in which the listed protein functions (Fig. 1). Each line in the table lists the known orthologs or functional analogs. Horizontal dashed lines between proteins indicate functional co-complexes; slashes between proteins indicate paralogs. Proteins in parentheses represent known homologs, but their function has not yet been experimentally established in that step; where a homolog is not listed, it was shown to not function in that step.

${ }^{a}$ The complexity of interactions between the RAD51 paralogs precludes a comprehensive listing of their interactions and, consequently, they are shown here separated by slashes; see text for details.

${ }^{\mathrm{b}}$ Does not mediate replacement of RPA by RAD51, but does possess DNA annealing functions analogous to RecQ and Rad52.

${ }^{\mathrm{c}}$ At up to stoichiometric concentrations; inhibitory beyond.

${ }^{\mathrm{d}}$ Protein-free joint molecules only.

${ }^{\mathrm{e}}$ Not tested, but protein is a structural or functional analog. 
S.C. Kowalczykowski

(RPA) (Pâques and Haber 1999; Symington 2002; Heyer et al. 2010). The RecF pathway and RAD52 group of proteins are remarkably conserved functionally, but not always structurally (Table 1) (Schiller et al. 2014). Conceptual and technical advances in yeast genetics and cell biology permitted physical analysis and cytological observation of the DNA intermediates of recombination and the proteins associated with these intermediates. Such studies enabled elucidation of the temporal order of events in vivo and the alignment of these steps with in vitro biochemical analyses (Haber 1995; Lisby et al. 2004; Lisby and Rothstein 2015).

\section{Human}

In humans, the proteins that effect recombinational DNA repair are remarkably conserved with those found in S. cerevisiae, but there are some notable exceptions and there is also greater complexity, with a larger potential for overlap or specialization of functions (Table 1 ). In addition to the core proteins that are homologous to proteins in yeast (RAD50, RAD51, RAD52, RAD54, MRE11, NBS1, MUS81, EME1, EME2, BLM, TOP3, RMI1, DNA2, EXO1, and RPA), there are five homologs of the RecQ helicases (BLM, RECQ1, RECQ4, RECQ5, and WRN) (Bizard and Hickson 2014); multiple RAD51 paralogs (RAD51B, RAD51C, RAD51D, XRCC2, and XRCC3, and possibly SWS1, SWSAP1, SWI5, and SFR1) (Daley et al. 2014b; Zelensky et al. 2014); two EXO1 proteins (EXOla and EXO1b) (Tishkoff et al. 1998); two RMI proteins (RMI1 and RMI2) (Bizard and Hickson 2014); and two topoisomerase III enzymes (TOPIII $\alpha$ and TOPIII $\beta$ ) (Bizard and Hickson 2014). Mutations at the BLM,WRN, and RECQ4 loci are responsible for Bloom's, Werner's, and Rothmund-Thomson/RAPIDILINO/Baller-Gerold syndromes, respectively. Mutations in these proteins result in genome instability that is manifest by cancer or premature aging (Brosh 2013). In addition, many more proteins, not present in yeast, are important to human recombinational DNA repair: these include the tumor suppressors, BRCA1, BRCA2 (FANCD1), and PALB2 (FANCN) (Prakash et al. 2015). These proteins are also involved in DNA crosslink repair, a process that intersects and overlaps with recombinational DNA repair (Kottemann and Smogorzewska 2013). Others include BRIP1/BACH1/ FANCJ, a Rad3-like helicase that interacts with BRCA1, and FANCM. In humans, BRCA1 is involved at a step of resection or just thereafter. Interestingly, human BRCA2 assumed the role of RAD51-mediator, while concomitantly, human RAD52 lost its mediator function but retained its functions in ssDNA annealing (see below and Zelensky et al. 2014).

\section{PROCESSING OF DNA BREAKS: INITIATION OF RECOMBINATION}

Although DNA sequence information is stored and preserved as duplex DNA, it is generally read in the form of ssDNA. In recombination as well, the homology search and DNA pairing by RecA/RAD51 require its assembly onto ssDNA (Bianco et al. 1998; Morrical 2015). Consequently, processing of broken DNA to produce ssDNA sufficient for RecA/RAD51 filament assembly and for homologous DNA recognition is essential. This processing is not left to chance degradation or unwinding, but rather involves targeted recombination-specific helicases and nucleases (Symington 2014).

\section{Bacteria}

In most bacteria, the two helicases primarily involved in resection are RecBCD (and analogs) (Chédin and Kowalczykowski 2002; Dillingham and Kowalczykowski 2008) and RecQ (Spies and Kowalczykowski 2005), although UvrD (helicase II) and HelD (helicase IV) can partially substitute in the absence of RecBCD and RecQ (Mendonca et al. 1995). RecBCD enzyme also possesses an intrinsic nuclease activity that is regulated by the recombination hotspot $\chi$ (Chi) (Dillingham and Kowalczykowski 2008). E. coli RecQ is the founding member of a broad class of ubiquitous, structurally related helicases. It is a $3^{\prime} \rightarrow 5^{\prime}$ DNA helicase that functions in the RecF pathway (Nakayama et al. 1984; Harmon and Kowalczykowski 1998) and unwinds all forms of double-stranded DNA (dsDNA), 
even covalently closed dsDNA (Harmon et al. 1999; Harmon and Kowalczykowski 2001). RecQ acts in conjunction with RecJ (Handa et al. 2009b), which is a $5^{\prime} \rightarrow 3^{\prime}$ exonuclease with a preference for ssDNA (Lovett and Kolodner 1989) but which can also act on dsDNA with a $5^{\prime}$-overhang (Han et al. 2006; Handa et al. 2009b). RecQ and RecJ coordinate their biochemical activities to resect DNA from ends that are not ideal for either protein alone (Morimatsu and Kowalczykowski 2014). In addition, they enlarge SSGs resulting from stalled replication caused by UV-induced DNA damage, by degrading the nascent lagging strand as a prelude to RecA-dependent daughter strand gap repair needed for resumption of replication (Courcelle and Hanawalt 1999).

RecBCD is the initiating member of a family of related multimeric helicases-nucleases found in most bacteria (Rocha et al. 2005), but with disparate, seemingly unrelated, names (e.g., AddAB for ATP-dependent DNase and RexAB for recombination exonuclease) (Dillingham and Kowalczykowski 2008). The E. coli enzyme functions in recombinational DSB repair and, paradoxically, degradation of foreign DNA (Smith 1991; Kuzminov 1999; Spies and Kowalczykowski 2005; Dillingham and Kowalczykowski 2008). The nuclease activity of RecBCD is responsible for creating degraded DNA that is used by the CRISPR immunity system for acquisition of the new short DNA sequences into the CRISPR array for use against phages and foreign DNA (Levy et al. 2015). RecBCD is a heterotrimeric complex that binds to a dsDNA end with 0.1 to $1 \mathrm{nM}$ affinity and with $>1000$ fold specificity over internal dsDNA (Roman and Kowalczykowski 1989b). It unwinds DNA at up to $1500 \mathrm{bp} / \mathrm{sec}$ for $\sim 30 \mathrm{kbp}$ before dissociating (Roman and Kowalczykowski 1989b; Bianco et al. 2001; Spies et al. 2003, 2007; Liu et al. 2013). It has two motor subunits, RecB and $\mathrm{RecD}$, each with opposite translocation polarities (RecB translocates $3^{\prime} \rightarrow 5^{\prime}$ and $\operatorname{RecD}$ translocates $5^{\prime} \rightarrow 3^{\prime}$ ), each traveling on a complementary strand at a different speed, and consuming $\sim 1$ molecule of ATP per bp unwound (Roman and Kowalczykowski 1989a; Dillingham et al. 2003; Taylor and Smith 2003; Dilling- ham et al. 2005; Spies et al. 2005, 2007). This multitude of activities is easily understood if one views RecBCD as a prototypic DNA helicase with an associated, concurrent, ssDNA endonuclease activity. Because of its two-motor architecture, RecBCD produces growing "loop-tails" or "twin-loops" structures that provide ready access to ssDNA-binding proteins (Taylor and Smith 1980; Telander Muskavitch and Linn 1982; Spies et al. 2007).

The recombination hotspot, $\chi$, is a regulatory sequence that controls RecBCD functions (Dixon and Kowalczykowski 1991, 1993); in doing so, it switches RecBCD from a primarily degradative mode to a recombination mode that preserves the ssDNA beyond $\chi$ and loads RecA onto that strand. The $\chi$ sequence is recognized as ssDNA within dsDNA by the translocating RecBCD (Ponticelli et al. 1985; Bianco and Kowalczykowski 1997). Recognition attenuates the vigorous $3^{\prime} \rightarrow 5^{\prime}$ nuclease activity of RecBCD, but it activates a weaker $5^{\prime} \rightarrow 3^{\prime}$ nuclease activity (Dixon and Kowalczykowski 1991; Anderson and Kowalczykowski 1997a). Thus, $\chi$ not only reduces the overall nucleolytic activity of RecBCD, but it also switches the polarity of DNA strand degradation (Anderson and Kowalczykowski 1997a). As a result, the $3^{\prime}$ terminated DNA strand downstream from $\chi$ is preserved. The $\chi$-activated RecBCD directs the loading of RecA onto this $\chi$-containing ssDNA, to the exclusion of the competitor, ssDNA-binding protein (SSB) (Anderson and Kowalczykowski 1997b; Churchill et al. 1999). These changes elicited by $\chi$-recognition are the consequences of a seemingly simple, although molecularly complex, mechanism wherein binding of the $\chi$ sequence to the RecC subunit results in a "latch" opening from which follows a cascade of structural changes (Handa et al. 2012; Yang et al. 2012; Krajewski et al. 2014).

Members of the SMC-family (structural maintenance of chromosomes) play important roles in recombinational DNA repair. Perhaps the best known is Rad50, which is discussed below. Interestingly, there are three bacterial SMC-family members in bacteria, the SbcCD complex, RecF, and RecN (Schiller et al. 2014). $\mathrm{SbcC}$ and $\mathrm{SbcD}$ are structurally similar to eu- 
S.C. Kowalczykowski

karyotic Rad50 and Mre11, respectively, and the complex cleaves hairpin DNA (Sharples and Leach 1995; Connelly et al. 1998). RecF is described in more detail below. RecN is a component of RecF-pathway as defined by its requirement for conjugational recombination in recBC $s b c B C$ strains (Picksley et al. 1984). The function of $E$. coli $\mathrm{RecN}$ is largely unknown, but RecA is reported to recruit RecN to a DSB (Keyamura et al. 2013). RecN, like RecF and Rad50, is an SMC-like protein, although the hinge-regions of RecN and RecF are much shorter than those other SMC proteins (Pellegrino et al. 2012; Schiller et al. 2014). In B. subtilis, RecN appears early at DSBs implying a role in bridging of the unprocessed broken DNA ends (Sanchez et al. 2006). Purified RecN is an ssDNAdependent ATPase that binds to DNA ends (Sanchez et al. 2008) and the Deinococcus protein stimulates the intermolecular ligation of linear DNA (Reyes et al. 2010).

\section{Yeast}

In $S$. cerevisiae, resection of DSBs occurs through the action of three distinct but genetically and biochemically overlapping machineries (Symington 2014). These are the Mre11-Rad50-Xrs2 complex (MRX) and Sae2 (MRX-Sae2); the Sgs1-Top3-Rmi (STR) and Dna2 complex (STR-Dna2) together with RPA; and Exonuclease 1(Exo1), which bears no relationship to the bacterial exonuclease I.

The most enigmatic of these complexes, at least historically, must be MRX. As mentioned above, Rad50 and Mre11 are structurally similar to SbcC and SbcD, respectively (Sharples and Leach 1995; Schiller et al. 2014). Biochemically, MR and MRX comprise a $\mathrm{Mn}^{2+}$-dependent exonuclease with a $3^{\prime} \rightarrow 5^{\prime}$ degradation polarity (Paull and Gellert 1998), which is the opposite expected from biological considerations. This apparent incompatibility is reconciled by models whereby MRX incises endonucleolytically on dsDNA distal to the DSB, and then digests from the nick to the DNA end in a $3^{\prime} \rightarrow 5^{\prime}$ direction to leave a $3^{\prime}$-overhang on the complementary strand (Garcia et al. 2011). Although MRX itself is a nuclease, manifestation of its endonuclease requires activation by the Sae 2 protein and $\mathrm{Mg}^{+2}$ (Cannavo and Cejka 2014), nicely resolving the paradox. MRX, after activation by Sae2, resects dsDNA only a few hundred nucleotides, but this resection is sufficient for gene conversion (Mimitou and Symington 2008; Zhu et al. 2008; Symington 2014). MRX is essential for resection when DNA breaks are chemically induced, but not when the breaks are cleanly made by $\mathrm{HO}$ endonuclease. However, when MRE11 is deleted, there is a delay in resection of clean breaks by the remaining resection enzymes, but not when a point mutation is introduced to eliminate nuclease activity. These findings are compatible with recruitment of STR-Dna2 and Exol by MRX to the DNA end as shown in vitro (Cejka et al. 2010a; Niu et al. 2010).

Members of the RecQ-family are found in most organisms (Bizard and Hickson 2014). In S. cerevisiae, there is one ortholog, the Sgs1 helicase (Gangloff et al. 1994). Full-length Sgs1 is the most active RecQ-helicase isolated to date (Cejka and Kowalczykowski 2010). It is involved in both the initial resection step of homologous recombination (Cejka et al. 2010a; Niu et al. 2010) and the final separation of a dHJ by dissolution (Cejka et al. 2010b; Bizard and Hickson 2014). The helicase and resection functions of Sgs1 require yeast RPA, are stimulated by interaction with MRX both in vitro and in vivo, and are also stimulated in vitro by Top3-Rmi1, which are essential in vivo (Mimitou and Symington 2008; Zhu et al. 2008; Cejka et al. 2010a; Niu et al. 2010; Chen et al. 2013).

Whereas Sgs1 is the helicase component of the STR-Dna2 resection machine, Dna2 is the essential nuclease. Dna2 is a helicase-nuclease that was initially noted to have sequence similarity to SF1 helicases and to possess a nuclease domain superficially similar to RecB (Budd et al. 2000). However, Dna2 actually resembles an AddB/RecD-hybrid, comprising an ironsulfur nuclease (Yeeles et al. 2009) and a $5^{\prime} \rightarrow 3^{\prime}$ helicase, rather than a $3^{\prime} \rightarrow 5^{\prime}$ helicase as in RecB (Cejka et al. 2010a). In addition to the aforementioned $5^{\prime} \rightarrow 3^{\prime}$ helicase, Dna2 has both $3^{\prime}$ - and 5'-exo/endonuclease activities (Bae et al. 1998; Budd et al. 2000). For resection, the helicase activity of Dna2 is dispensable but 
not its nuclease activity. Dna2 also directly interacts with Sgs1. The nuclease activity of Dna2 is regulated by specific interaction with RPA to suppress the $3^{\prime} \rightarrow 5^{\prime}$ degradation, leaving only the $5^{\prime} \rightarrow 3^{\prime}$ nuclease activity (Bae et al. 2001; Cejka et al. 2010a; Niu et al. 2010). The coordinated activity of STR-Dna2 and RPA can resect thousands of nucleotides (up to 20,000 in vivo). Despite the many differences between the components of bacterial and eukaryotic resection machinery, the Sgs1-Dna2-RPA complex mimics the functions of $\chi$-modified RecBCD to produce $3^{\prime}$-tailed resected DNA (Cejka et al. 2010a). After $\chi$-recognition, RecB is the lead helicase subunit, unwinding $3^{\prime} \rightarrow 5^{\prime}$; the nonessential RecD motor travels more slowly $5^{\prime} \rightarrow 3^{\prime}$ on the opposite strand; and the nuclease domain is threaded onto the $5^{\prime}$-end of a DNA strand and cleaves endonucleolytically. Sgs1Dna2 provides these functions, respectively, in a constitutive (sequence-independent), twomotor, single-nuclease complex. In addition, it is known that Sgs1 interacts directly with Rad51 (Wu et al. 2001). It is intriguing to speculate that Sgs1 might also coordinate the loading of Rad51 onto the ssDNA produced by STR-Dna2-RPA. Therefore, the STR-Dna2-RPA complex comprises a functional analog of RecBCD/AddAB.

The third means of resecting DNA is via Exo1. Eukaryotic Exo1 is a $5^{\prime} \rightarrow 3^{\prime}$ dsDNA exonuclease, and a member of the XPG-family (Szankasi and Smith 1992). It can resect thousands of nucleotides in reactions that are stimulated by RPA and MRX both in vitro and in vivo (Cannavo et al. 2013; Chen et al. 2013). In contrast to STR-Dna2, stimulation of Exo1 by RPA is not species-specific, implying that stimulation results from elimination of an inhibition of Exol by titration with the ssDNA product. Resection of DNA by Exo1 is not synergistic with STR-DNA2 and, in fact, is competitive (Cannavo et al. 2013).

Chromatin structure has a profound effect on DNA resection. The chromatin remodeling/ regulating protein complexes Fun30, Ino80, and Rsc have partially overlapping functions in facilitating DSB resection (Chen et al. 2012; Costelloe et al. 2012; Eapen et al. 2012). Loss of all three of these chromatin remodeling activities leads to nearly complete elimination of resection but, as individual mutations, fun $30 \Delta$, has the most severe impact, implying that Fun30 is the major ATP-dependent remodeling factor needed for resection of DSBs by both STRDna2 and Exo1. The loss of Fun30 function alone results in a three- to fourfold reduction in resection (Eapen et al. 2012).

\section{Human}

In humans, the mechanisms of DNA resection are very similar to those in S. cerevisiae, but with potentially added complexity (Symington 2014). There is a homolog of MRX, which is MRE11, RAD50, and NBS1 (MRN), and a limited homolog of Sae2, which is CtIP. There are 5 potential homologs of Sgs1 in humans: RECQ1, BLM, WRN, RECQ4, and RECQ5 proteins (Bizard and Hickson 2014). BLM is the clear human ortholog of Sgs1, based largely on the facts that it interacts with human DNA2 to promote DSB resection and also with human TOPO III $\alpha$, RMI1 and RMI2 (TRR) to promote topological dissolution of dHJs (Wu et al. 2000, 2006a; Wu and Hickson 2003; Nimonkar et al. 2008, 2011). Finally, there is a clear ortholog of Exo1, which is also known as EXO1 (although also designated HEX1 [Wilson et al. 1998]) (Schmutte et al. 1998; Tishkoff et al. 1998).

DSB resection by the human complexes follows much of the paradigm established by the biochemical and genetic analyses in yeast. The MRN complex is also a $\mathrm{Mn}^{2+}$-dependent exonuclease that resects dsDNA $3^{\prime} \rightarrow 5^{\prime}$ (Paull and Gellert 1999), and it is regulated by CtIP (Sartori et al. 2007). Interestingly, CtIP interacts with BRCA1, a protein that is also implicated at some as yet undefined step of DNA resection (Yu et al. 1998). It remains unclear how CtIP affects MRN function, but analogies to the yeast homologs seem compelling (Cannavo and Cejka 2014).

In humans, there is machinery analogous to yeast STR-Dna2. BLM and DNA2 also interact physically to resect DNA; the reaction is specific to BLM in that none of the other human RecQhelicases can substitute at the initial step of resection of blunt-ended DNA (Nimonkar et al. 
2011). Resection requires the helicase activity of BLM and nuclease activity of DNA2, but the helicase activity of DNA2 is dispensable. The $5^{\prime} \rightarrow 3^{\prime}$ polarity of resection by BLM-DNA2 is maintained by RPA. In addition, RPA is an essential component for efficient DNA unwinding by BLM. The helicase activity of BLM is further stimulated by the TOPO III $\alpha$-RMI1RMI2 complex (Daley et al. 2014a) and also by DNA2, just as in the case of Sgs1. Recruitment by MRN increases the affinity of BLM for DNA ends by 2.5- to 10-fold (Nimonkar et al. 2011). Furthermore, BLM interacts with RAD51 (Wu et al. 2001), leaving open the possibility of directed loading of RAD51 onto the newly resected ssDNA.

WRN can also interact with DNA2 (Sturzenegger et al. 2014). Although WRN cannot initiate DSB resection at blunt-end DNA (Nimonkar et al. 2011; Sturzenegger et al. 2014), WRN does contribute to resection of partially resected DNA in vitro (Sturzenegger et al. 2014) and in vivo (Tomimatsu et al. 2012), showing that these two RecQ-helicases cooperate to promote the long-range resection of a DSB.

Humans also possess a second means for long-range resection that requires EXO1. Either isoform of EXO1 resects dsDNA and is stimulated by BLM, MRN, and RPA (Nimonkar et al. 2011). BLM increases the affinity of EXO1 for ends by a mechanism that is independent of BLM helicase function, but BLM does not alter the processivity of EXO1 (Nimonkar et al. 2008, 2011). The product of resection can be used by RAD51 to promote formation of joint molecules that remain refractory to disruption by BLM helicase action (Nimonkar et al. 2008). MRN increases the processivity of EXO1, suggesting that it may remain associated with EXO1 as a co-complex, as resection progresses. CtIP also interacts with EXO1 to increase resection of DSBs (Eid et al. 2010). It remains to be determined whether stimulation by MRNCtIP is synergistic. Nonetheless, as in yeast, although MRN and CtIP stimulate resection in vivo (Tomimatsu et al. 2012), they are not essential for resection by EXO1, showing that cleavage by MRN is not a necessary precursor to resection for some breaks, presumably those with clean-ends. In a further parallel to the yeast system, the human equivalent of Fun30, SMARCAD1, is needed for resection in vivo (Costelloe et al. 2012).

DSB resection in humans is subject to a complex network of cell cycle-dependent control. In addition to the regulation of MRN via phosphorylation of CtIP by cyclin-dependent kinase $(\mathrm{CDK})$ and deacetylation by human SIRT6 (Sartori et al. 2007; Huertas and Jackson 2009; Kaidi et al. 2010), there are several competing proteins as well as inhibitory nucleosome structure. The protein 53BP1 prevents resection by binding to the DSB (Bothmer et al. 2010; Bunting et al. 2010). 53BP1 is, in turn, regulated by RIF1, a protein that interacts with 53BP1 to enforce a block to resection and to favor repair by the competing alternative pathway, NHEJ (Chapman et al. 2013; Escribano-Diaz et al. 2013; Zimmermann et al. 2013); the mechanism involves both recruitment and complex formation with modified nucleosomes that is beyond the scope of this review (see Panier and Boulton 2014; Zimmermann and de Lange 2014). BRCA1 is normally needed for resection, but its absence can be suppressed by depletion of 53BP1 or RIF1 (Escribano-Diaz et al. 2013).

\section{DNA PAIRING AND DNA ANNEALING}

After DSB resection, a RecA or RAD51 filament is assembled on the resultant ssDNA. The RecA/ RAD51 family of proteins is ubiquitous (Morrical 2015). These are modest proteins as monomers $(\sim 40 \mathrm{kDa})$, but they assemble into an indefinite filament on DNA that displays a remarkable array of complex activities (Kowalczykowski and Eggleston 1994; Bianco et al. 1998; Cox 2007). The most unique and relevant function is ATP-dependent homologous DNA pairing and strand exchange. This activity requires formation, in its simplest form, of an ATPbound filament of RecA/RAD51 on ssDNA (the so-called "presynaptic complex" because it forms before the DNA pairing, or "synaptic," step). The RecA and RAD51 filaments differ in many details, but they share the common features of binding 3 nucleotides of ssDNA to form a right-handed helical filament comprising $\sim 6$ 
monomers per turn (Stasiak and Egelman 1994). The active form of RecA/RAD51 requires bound ATP and this filament has a pitch of $\sim 9.5 \mathrm{~nm}$ (though polymorphic) and the DNA is extended $\sim 1.5$-fold relative to B-form DNA dimensions. An inactive complex is formed with ADP wherein the filament is $\sim 6.5 \mathrm{~nm}$ and condensed. ATP hydrolysis is not needed for DNA strand exchange; rather, ATP hydrolysis permits conversion to the inactive ADP-form, which is also less stable and which promotes disassembly (Menetski and Kowalczykowski 1985; Menetski et al. 1990; van Mameren et al. 2009).

The presynaptic complex is the active species that searches for DNA sequence homology and that mediates the pairing and exchange of DNA strands. The assembly of RecA/RAD51 onto DNA proceeds by nucleation and growth (Cazenave et al. 1983; Galletto et al. 2006; Joo et al. 2006; Miné et al. 2007; Modesti et al. 2007; Hilario et al. 2009; Bell et al. 2012; Candelli et al. 2014). Although capable of forming filaments on naked ssDNA, filament formation by RecA/ RAD51 protein is affected, both positively and negatively, by ssDNA-binding proteins and by a growing list of regulatory proteins (see below).

RecA/RAD51 have a love-hate relationship with SSB/RPA. SSB/RPA are members of a ubiquitous class of ssDNA-binding proteins that have no enzymatic activity but that bind ssDNA cooperatively and nonspecifically (Lohman and Ferrari 1994; Wold 1997; Shereda et al. 2008; Chen and Wold 2014). These proteins can stimulate DNA strand exchange overall (Cox et al. 1983; Sugiyama et al. 1997). Stimulation is a consequence of the helix-destabilization properties of SSB/RPA, which removes the DNA secondary structure that hinders complete presynaptic complex formation (Sugiyama et al. 1997; Sung 1997). SSB/RPA also stimulate joint molecule formation and DNA strand exchange by binding to the displaced ssDNA strand, preventing reversal of the strand exchange (Lavery and Kowalczykowski 1992; Eggler et al. 2002). Paradoxically, SSB/RPA kinetically inhibit presynaptic complex formation when they are bound to ssDNA before assembly of the filament (Kowalczykowski and Krupp 1987; Kowalczy- kowski et al. 1987; Sugiyama et al. 1997; Sung 1997). The DNA strand exchange protein must displace the SSB in a slow process that can be accelerated by a mediator protein (see below).

\section{Bacteria}

The behavior of RecA has been both studied and reviewed extensively in the past (Kowalczykowski and Eggleston 1994; Bianco et al. 1998; Cox 2007). Most recently, long-standing unresolved questions have been resolved by single-molecule approaches, summarized here. The assembly of RecA onto single molecules of DNA can be detected by a variety of methods. Initial studies used changes in either the length of DNA because of RecA binding, or the force-extension behavior of the DNA (Léger et al. 1998; Hegner et al. 1999; Shivashankar et al. 1999; Fulconis et al. 2006); not only did these experiments establish feasibility, but they showed that nucleation and growth was more distinct than in traditional ensemble biochemical studies. Assembly was cooperative in RecA concentration, and disassembly could be slowed by pulling on the DNA, consistent with the structural finding that RecA extended DNA when bound; a single-filament underwent transitions between the extended ATP structure and the compressed ADP filament, firmly establishing the flexibility of filaments that were turning over ATP (van Loenhout et al. 2009). Furthermore, it was inferred that within a RecA-dsDNA filament that was undergoing ATP hydrolysis, up to $32 \%$ of the DNA was free to rotate or move within the filament (Hegner et al. 1999).

Single-molecule fluorescence based on Förster resonance energy transfer (FRET) showed that a RecA filament grows by addition of monomer to an end, but with faster addition to the $3^{\prime}$-end (Joo et al. 2006). Direct imaging of filament formation revealed that 3 to 5 monomers of RecA are needed to from a nucleus on dsDNA, which could readily grow bidirectionally and indefinitely at 2 to 7 monomers $/ \mathrm{sec}$ (Galletto et al. 2006; Handa et al. 2009a). When assembly on SSB-ssDNA complexes was imaged, nucleation was greatly reduced relative to naked ssDNA, showing that filament assem- 
bly is limited by SSB, consistent with decades of genetic and biochemical observations (Bell et al. 2012). Nucleation required only a dimer of RecA, whereas growth on ssDNA was also seen to be bidirectional, with a twofold bias for growth by monomer addition in the $5^{\prime} \rightarrow 3^{\prime}$ direction, in agreement with the FRET study. Interestingly, at physiological conditions, neither nucleation nor growth was occurring at the maximum rate, suggesting that selective pressure maintained a spontaneous rate of filament assembly that restricted uncontrolled filament formation in vivo. The mediator complex, RecFOR, which targets RecA to ssDNA on the $5^{\prime}$-side of a junction with dsDNA (Morimatsu and Kowalczykowski 2003; Morimatsu et al. 2012), increased nucleation of RecA and the RecOR complex, which mediates replacement of SSB by RecA via an interaction with SSB (Umezu et al. 1993), increased both nucleation and growth of the filament. The net consequence is that nucleation and growth are each increased about threefold, thus establishing key tenets for the action of mediators as catalysts of RecA filament formation on SSB-coated ssDNA (Bell et al. 2012).

Although RecA was shown to promote DNA strand exchange in vitro in 1979 (Shibata et al. 1979), the manner by which it found homologous DNA sequences, recognized sequence identities, and catalyzed exchange of DNA strands was not fully understood until recently. Single-molecule fluorescence microscopy revealed that two kinetic features ensure a rapid homology search. Direct imaging showed that the RecA filament makes multiple simultaneous nonhomologous contacts with dsDNA during the search process, conducting the search in a parallel manner by using the intrinsic polyvalency of the filament for dsDNA binding (Forget and Kowalczykowski 2012). In agreement, the search occurred about fourfold faster with filaments that were fourfold longer. In addition, the most efficient searching required that the dsDNA target could form a randomly coiled structure that maximized the number of contacts between the filament and the dsDNA. Even though the process seems to be superficially similar to a bulk "coaggregation" phenomenon that had been used to explain the rapidity of the homology search (Gonda and Radding 1983), macroscopic coaggregation is not needed for homologous pairing (Kowalczykowski and Krupp 1989; Kowalczykowski 1991); furthermore, subsequent analyses were more compelling and concluded that the rate-limiting step in ensemble studies was not the search step, but rather a step in dsDNA opening or strand exchange (Julin et al. 1986). To highlight the threedimensional nature of the newly illuminated search process, it was termed "intersegmental contact sampling." Homology sampling was envisioned to occur between randomly dispersed segments of dsDNA, using the capacity of the flexible RecA filament to make many contacts with flexible dsDNA within the sampling volume. Given that $\sim 15$ nucleotides of ssDNA, which is only one turn of a RecA filament, is sufficient for homologous pairing (Hsieh et al. 1992), a filament assembled on $1000 \mathrm{nt}$ of resected DNAwould have the potential capacity to search as many as $\sim 70$ sites in parallel if each could act independently, which could represent a 70-fold enhancement that would further increase if more DNA was resected. A single-molecule analysis of synapsis concluded that for a target site of $\sim 1 \mathrm{~kb}$, only $\sim 80 \mathrm{bp}$ of dsDNA were involved in a productive homologously paired displacement loop (D-loop) (van der Heijden et al. 2008). In another study, FRET was used to show that the RecA-ssDNA filament could undergo one-dimensional sliding on dsDNA, a behavior that is well established to accelerate the search kinetics for sequence-specific-binding proteins (Ragunathan et al. 2012). The filament could slide randomly over a mean distance of several hundred base pairs, providing an enhancement of target searching by $\sim 200$-fold. Thus, the RecA-ssDNA filament finds homology by randomly contacting many distant dsDNA segments using its multitude of secondary DNA-binding sites, and then uses local sliding to sample up to several hundred different sequences at that locus. This entire search process is completely independent of ATP hydrolysis (Menetski et al. 1990).

The manner by which DNA sequence homology is recognized has also advanced in un- 
An Overview of Recombination

derstanding recently, primarily by determination of structures of RecA-ssDNA and RecAdsDNA complexes (Chen et al. 2008). A crucial feature of these structures was the finding that the DNA is not extended isotropically within the filament, but rather it is organized in triplets, with each triplet (of either ssDNA or dsDNA) being separated by nearly complete extension of the phosphodiester backbone to a distance of $7.8 \AA$. The structures suggested that homologous recognition occurred in units of three nucleotides that pair with three base pairs. The large separation of $7.8 \AA$ immediately suggested an energetic proofreading process, in which the energy cost of stretching could be recovered if the next three nucleotides were homologous, but if not, then the nascent mispaired structure would dissociate. However, if they were homologous, then this microscopic recognition process would be favorable, and this testing of homology could continue in units of three until a stably paired complex was formed (Kowalczykowski 2008). Modeling, both early and recent, and single-molecule interrogation provided physical insight into the detailed energetics of the process and they predict a unique progression of pairing involving increments of three nucleotide/base pairs (Bertucat et al. 1998; Prévost and Takahashi 2003; Ragunathan et al. 2011; Peacock-Villada et al. 2012).

Although early studies showed that RecA has the capacity to anneal complementary ssDNA, this activity is completely abolished by SSB, rendering it unlikely to be of biological significance. In fact, a plethora of proteins can promote DNA annealing (Eggleston and Kowalczykowski 1991). However, in every case examined, save one, annealing is blocked by the binding of SSB to ssDNA. The exception is RecO, which possesses the unique capacity to anneal cognate SSB-ssDNA complexes (Kantake et al. 2002). $\mathrm{RecO}$ is the first member of a class of seemingly ubiquitous proteins that have the singular capacity to anneal complementary ssDNA that is complexed with its cognate SSB: these proteins include yeast Rad52, human RAD52, and T4 phage UvsY (Sugiyama et al. 1998; Kantake et al. 2002; Jensen et al. 2010).
Yeast

The yeast Rad51 protein manifests many of the same properties and behaviors as RecA, but there are notable differences. One is that ATP turnover by Rad51 is much slower, resulting in a filament that is less dynamic (Sung 1994). A second difference is that Rad51 has a greater affinity for dsDNA than RecA, resulting in formation of inhibitory Rad51-dsDNA complexes (Sung and Robberson 1995); in fact, both in vivo and in vitro, these nonproductive complexes are dissociated by the motor protein, Rad54 (Solinger et al. 2002; Shah et al. 2010). Finally, ensemble studies show that the net bias of Rad51 filament assembly is opposite to that of RecA, preferentially assembling in the $3^{\prime} \rightarrow 5^{\prime}$ direction (Sung and Robberson 1995). As for RecA, RPA will block assembly of Rad51 onto ssDNA, but it will also stimulate DNA pairing by binding to and stabilizing the displaced DNA strand (Sugiyama et al. 1997; Eggler et al. 2002). Similarly, the assembly and disassembly of Rad51 filaments is regulated by the status of the bound ligand: ADP complexes dissociate more quickly than ATP complexes (Robertson et al. 2009b).

The manner by which homology is found can be ascertained in vivo in yeast. Direct imaging of yeast cells, in which a DSB was introduced revealed a profound increase in the mobility of the break site, providing a means for sampling a 10-fold greater volume of chromosomal space by the Rad51 filament (Dion et al. 2012; MinéHattab and Rothstein 2012; Lisby and Rothstein 2015). In addition, the mobility of unbroken chromosomal sites also increased, about fourfold. These collective observations reveal a cellular mechanism that alters chromosomal structure and/or fluidity in a way that enhances movement of the Rad51 filament within a less constrained cellular environment to facilitate the homology search.

Recombinational DNA repair by the singlestrand annealing (SSA) and synthesis-dependent strand annealing (SDSA) pathways has been most intensively studied in $S$. cerevisiae (Mehta and Haber 2014). Rad52 is essential for these pathways. Like RecO, Rad52 promotes annealing of complementary ssDNA that is 
S.C. Kowalczykowski

complexed with yeast RPA and functions only with its cognate ssDNA-binding protein (Shinohara et al. 1998; Sugiyama et al. 1998). S. cerevisiae also has a second annealing protein, Rad59, that is a paralog of Rad52 and augments the capabilities of Rad52; the role of Rad59 is manifest when the complementary regions are short (Bai and Symington 1996; Petukhova et al. 1999; Sugawara et al. 2000; Wu et al. 2006b). Rad59, however, cannot reanneal RPA-ssDNA complexes on its own. Not only is ssDNA annealing function important to SSA and SDSA, but in the classic DSBR mechanism, the second end of the break can pair with the intact chromosome via either direct DNA strand invasion or by DNA annealing with the displaced ssDNA that is coated with RPA. Indeed Rad52 can promote capture of the second end, offering an alternative means of maturing the intermediates of DSB repair (Sugiyama et al. 2006; Lao et al. 2008; Nimonkar et al. 2009).

\section{Human}

The human ortholog, RAD51, behaves similarly to its yeast counterpart (Baumann et al. 1996; Baumann and West 1997). It promotes homologous DNA pairing and strand exchange in an ATP-dependent reaction that is stimulated by human RPA. ATP hydrolysis is comparable to yeast Rad51, and the polarity of pairing and invasion is the same, but as noted earlier, opposite to that of RecA.

The behavior of individual nucleoprotein filaments is also similar to that of yeast Rad51. In the presence of ATP, the human protein extends DNA by $\sim 50 \%-60 \%$, and assembles by nucleation and growth (Hilario et al. 2009; Candelli et al. 2014). Nucleation on DNA involves two to three monomers of RAD51, although larger nuclei could be detected on ssDNA. However, in contrast to RecA and Rad51, growth on dsDNA from individual nuclei did not occur indefinitely but rather stopped after addition of $\sim 2000$ monomers on bare DNA (Hilario et al. 2009). On hydrolysis of ATP, the resultant ADP-containing filaments shrink in a manner that is reversed upon subsequent ATP binding (Robertson et al. 2009a). Repeated cycles of ATP hydrolysis will cause dis- assembly of the RAD51 filaments, but this can be stopped by applying tension to the dsDNA (van Mameren et al. 2009). Disassembly did not occur monotonically in time, but rather was seen to occur in "bursts." These kinetics were interpreted as dissociation of multiple monomers from the filament end when those "capping" monomers had hydrolyzed the bound ATP.

Like yeast, there is a human RAD52 protein that has the capacity to catalyze annealing of ssDNA that is complexed with human RPA (Jensen et al. 2010). However unlike yeast, in which all of recombinational DNA repair is dependent on Rad52 because of its multiple functions, which include involvement both in SSA and SDSA and being a mediator of Rad51 filament assembly (see below), in human, the phenotypic consequences of RAD52 deletion are minimal, and revealed only in BRCA2-deficient cells (Feng et al. 2011). Although curious, the genetic findings are consistent with the biochemical behavior of human RAD52. Although RAD52 possesses the expected annealing functions, it has lost the capacity to mediate RAD51 assembly on RPA-ssDNA complexes (McIlwraith and West 2008; Jensen et al. 2010). This latter function has been acquired by BRCA2 (Jensen et al. 2010; Liu et al. 2010). This may suggest that second end capture in not mediated by annealing but rather a second DNA strand invasion event.

\section{MEDIATORS AND MODULATORS OF RecA/ RAD51 FILAMENT FORMATION}

Like all biological processes, recombination and its outcome are controlled. As already mentioned, there is both positive and negative regulation of recombination. The first formal "mediator," UvsY protein, was identified in bacteriophage T4 (Harris and Griffith 1989; Kodadek et al. 1989; Yonesaki and Minagawa 1989). The list of accessory proteins, which are both mediators and modifiers of RecA/RAD51 filaments and their functions, is being uncovered in a seemingly exponential manner, precluding an in-depth review (see Zelensky et al. 2014; Morrical 2015). Here, only a few examples of these proteins will be discussed to illustrate their range of behaviors and modes of action. 
Bacteria

In RecBCD-mediated recombination, E. coli solved the problem of mediating the delivery of RecA to DNA in a most direct and copacetic manner. Rather than deal with the competition of RecA and SSB for the ssDNA created by RecBCD action after the fact, RecBCD directly loads RecA onto the ssDNA as it is being created (Anderson and Kowalczykowski 1997b; Arnold and Kowalczykowski 2000). It achieves this loading via a cryptic RecA-binding site that is revealed upon $\chi$ recognition (Churchill and Kowalczykowski 2000). Loading is mediated by the $30 \mathrm{kDa}$ carboxy terminal nuclease domain $\left(\mathrm{RecB}^{\text {nuc }}\right.$ ) of RecB (Arnold and Kowalczykowski 2000; Churchill and Kowalczykowski 2000; Spies and Kowalczykowski 2006). This domain is connected to the main body of the protein by a 70-amino-acid flexible tether (Singleton et al. 2004). On $\chi$ recognition, the loading domain is released from its docking site, and binds a dimer of RecA, which is the minimum size for nucleation (Spies and Kowalczykowski 2006). By virtue of its proximity to the newly produced ssDNA, this domain delivers a RecA nucleus to the DNA before SSB binding. The RecA then grows with a bias toward the $3^{\prime}$-end of the ssDNA, which is opposite to the direction of RecBCD translocation. This loading presumably occurs repeatedly, allowing discontinuous growth of RecA filaments on the $\chi$-containing ssDNA. To better accommodate the slower RecA growth relative to RecBCD translocation speed, RecBCD reduces its translocation velocity after recognizing and pausing at $\chi$ (Spies et al. 2003). $\chi$ is therefore also a "molecular throttle" and it achieves this reduction in speed by switching motor usage to the RecB subunit (Handa et al. 2005; Spies et al. 2007). Thus, by coupling DNA resection directly to RecA loading in the same complex, RecBCD ensures efficient RecA filament formation without the need for intermediaries. It remains to be seen whether any of the eukaryotic machineries will mimic such a concerted and elegant coordination of these steps.

The RecF pathway for recombinational DNA repair is a close analog of the process in eukaryotes. As described earlier, RecQ and
RecJ resect dsDNA, and require SSB for efficient DNA unwinding. RecF, RecO, and RecR facilitate the assembly of RecA on SSB-ssDNA (Umezu et al. 1993; Umezu and Kolodner 1994; Morimatsu and Kowalczykowski 2003; Handa et al. 2009b; Bell et al. 2012; Morimatsu et al. 2012). These proteins function as two different subcomplexes, RecFOR and RecOR. The RecFOR complex facilitates the loading of RecA onto an SSB-ssDNA complex specifically at the junction between ssDNA and dsDNA (Morimatsu and Kowalczykowski 2003; Morimatsu et al. 2012). RecF binds to and recognizes the $5^{\prime}$-side of the junction, and $\mathrm{RecO}$ interacts in a species-specific manner with SSB (Umezu and Kolodner 1994; Morimatsu and Kowalczykowski 2003). This heterotrimeric complex then recruits RecA to the junction, facilitating its nucleation by threefold, and growth in the presence of RecOR by another threefold, to permit formation of a filament that extends up to $1-2 \mathrm{~kb}$ from the junction (Bell et al. 2012; Morimatsu et al. 2012). The RecOR complex acts in a structure-independent manner to load RecA onto SSB-ssDNA by increasing both nucleation (about twofold) and growth (about threefold).

The RecA filament is also under negative control to limit inappropriate recombination by long-lived RecA filaments. The paradigm for this concept comes from S. cerevisiae (see below), in which both genetic and biochemical studies established the Srs2 helicase as a motor protein that disassembles Rad51-ssDNA filaments (Krejci et al. 2003; Veaute et al. 2003). The bacterial ortholog of Srs 2 is UvrD, which is a $3^{\prime} \rightarrow 5^{\prime}$ helicase originally identified based on its role in UV-lesion repair. Indeed, UvrD disassembles RecA-ssDNA filaments in an ATP-hydrolysis dependent fashion (Veaute et al. 2005; Petrova et al. 2015). Similar to yeast, the inviability of $u v r D$ rep double mutants is caused by RecA, and this inviability is suppressed by loss of RecFOR mediator functions (Veaute et al. 2005).

There are also proteins that bind to the RecA filament and, in doing so, stabilize or destabilize the filament (Lusetti et al. 2004b). One such protein is DinI, which is DNA-damage inducible. At an amount stoichiometric with RecA, 
S.C. Kowalczykowski

DinI stabilizes RecA filaments by binding to the carboxyl terminus of RecA within the filament, but at higher concentrations, it can bind within the groove of the filament by mimicking ssDNA, and destabilize the filament (Voloshin et al. 2001; Galkin et al. 2011); the physiological levels of DinI are at the lower end of this phenomenon. On the other hand, RecX destabilizes the filament by preventing filament growth, resulting in depolymerization, and it functions in many bacterial species to modulate the activity of RecA (Stohl et al. 2003; Lusetti et al. 2004a). In this regard, RecX, and perhaps DinI, function may be analogous to PCNA-associated recombination inhibitor (PARI), which destabilizes human RAD51 filaments (Moldovan et al. 2012).

Yeast

In $S$. cerevisiae, the number of proteins that modify Rad51 assembly or alter filament stability increases by several-fold over the bacteria: these include Rad52, Rad54, Rad55-Rad57 dimer, Rdh54/Tid1, Shu1, Shu2, Psy3, and Csm2 (the latter four comprise the "Shu" or "PCSS" complex).

Rad52 is the prototypic eukaryotic mediator protein (Sung 1997; New et al. 1998; Shinohara and Ogawa 1998). Rad52 accelerates assembly of a Rad51 filament on ssDNA that is complexed with RPA. Stimulation results from a species-specific interaction with both the RPA and Rad51. Although the mechanism of this process has not been elaborated in detail, it is likely that the process will parallel the behavior of RecOR wherein both nucleation and growth of the filament are increased.

S. cerevisiae Rad55 and Rad57 are two Rad51 paralogs. These proteins purify as the heterodimeric complex, Rad55-Rad57 (Sung 1997). These proteins are homologous to Rad51 only within the RecA-core, which contains the ATP binding and hydrolysis motifs; otherwise, there is little homology with each other or with Rad51. Mutations in RAD55 and RAD57 show similar sensitivity to DNA-damaging agents and are defective for recombination (Lovett and Mortimer 1987). Mutations in Rad55-Rad57 reveal two suggestive genetic features: the phenotypes can be suppressed by either overexpressing Rad51 (Johnson and Symington 1995) or by expressing a Rad51 mutant that has an enhanced ability to form filaments (Fortin and Symington 2002). These properties are informative because they precisely parallel the types of suppressors of recFOR function in E. coli (Madiraju et al. 1988; Thoms and Wackernagel 1988). Thus, it appears likely that Rad55-Rad57 participate in recombination by enabling nucleation and/or growth of Rad51 filaments on RPA-ssDNA, although they can also act by preventing dissociation too. Indeed, Rad55-Rad57 are incapable of promoting DNA strand exchange, but they do stimulate DNA strand exchange when RPA is present (Sung 1997).

Recently, a new role for Rad55-Rad57 was discovered (Liu et al. 2011a). As mentioned above, genetic analyses revealed that mutations in RAD51 suppressed the radiation sensitivity of SRS2 loss, leading to the conclusion that Srs2 helicase reversed Rad51-ssDNA complexes or some other recombination intermediates (Aboussekhra et al. 1992; Chanet et al. 1996). Srs2 was indeed found to be an antirecombination motor protein with the capacity to dissociate Rad51 filaments in vitro (Krejci et al. 2003; Veaute et al. 2003), establishing a paradigm of negative control in recombination. Moreover, recently it was found that Rad55Rad57 blocked disassembly of the Rad51 filament by Srs2 (Liu et al. 2011a). In accord with this novel function for Rad55-Rad57, deletion of SRS2 suppressed the radiation sensitivity of a rad55 or rad57 mutation (Liu et al. 2011a). The negative regulation of a negative regulator of recombinational DNA repair highlights the complexity of the process, and the clear cellular need to control this process.

In addition to $\operatorname{Rad} 55-\operatorname{Rad} 57$, there are at least two more Rad51 paralogs in yeast, Shu1 and Psy3 (Shor et al. 2005). These proteins form a complex with Shu2 and Csm3 to complete the Shu complex (Sasanuma et al. 2013). Psy3 and Csm2 form a stable heterodimeric subcomplex. Although Psy3 and Csm2 have no sequence similarly to RecA/RAD51, their structure resembles a near exact copy of a dimer 
of the RecA/RAD51 core (Tao et al. 2012; Sasanuma et al. 2013); thus, they are clearly structural paralogs. Based on their genetic and biochemical attributes, it is evident that the Shu complex stabilizes the Rad51 filament, but through a mechanism yet to be revealed (Sasanuma et al. 2013).

Rad54 is unique to the eukaryotes. It belongs to the Swi2/Snf2 family of ATP-dependent chromatin remodeling proteins (Flaus et al. 2006). Rad54 displays a multitude of activities in vitro (Ceballos and Heyer 2011). Rad54 is a dsDNA translocase that can translocate at speeds of $\sim 300 \mathrm{bp} / \mathrm{sec}$ for distances of $\sim 10 \mathrm{kbp}$ (Amitani et al. 2006). It binds to Rad51-ssDNA filaments to facilitate homologous pairing at an early step in the repair process (Petukhova et al. 1998; Mazin et al. 2000). The binding of Rad54 to the filament confers increased stability to the Rad51-ssDNA in an ATP hydrolysis-independent manner (Mazin et al. 2003), illustrating a manner of stabilization that bears resemblance to the action bacterial DinI.

Rdh54 (Tid1) is a Rad54 paralog that shares many features of Rad54 (Brown and Bishop 2015). Its biological functions are overlapping but different, with Rdh54 having a major role in meiosis. Rdh54 is also dsDNA translocase that can travel $\sim 10 \mathrm{kbp}$, albeit more slowly than Rad54 at $\sim 85 \mathrm{bp} / \mathrm{sec}$ (Nimonkar et al. 2007; Prasad et al. 2007). Rdh54 can stimulate the pairing activity of both Rad51 and the meiosisspecific paralog, Dmcl (Petukhova et al. 2000; Chi et al. 2009) through both changes in DNA supercoiling and also by stabilizing the Dmc1 nucleoprotein filament (Nimonkar et al. 2012).

\section{Human}

In moving to humans, there is another fold increase in complexity. The human proteins that do or could modify RAD51 assembly or stability include BRCA2, RAD51B, RAD51C, RAD51D, XRCC2, XRCC3, RAD52, PALB2, SWS1, SWSAP1, RAD54, RAD54B, SWI5, and SFR.

The full-length human BRCA2 shows a robust mediator function in vitro, as defined by its capacity to promote assembly of RAD51 onto
ssDNA complexed with RPA (Jensen et al. 2010; Liu et al. 2010). In this regard, BRCA 2 has clearly usurped the mediator function from RAD52, but not the annealing function (Jensen et al. 2010). However, the manner by which BRCA2 promotes assembly is different from the canonical picture describe above for $\mathrm{RecO} / \mathrm{Rad} 52$. BRCA2 does not interact with either RPA or RAD52; however, it does bind at least six monomers of RAD51 and likely up to eight, in a species-specific manner, via its eight BRC repeats. BRCA2 also binds to any ssDNA with high affinity $\left(K_{\mathrm{d}} \sim \mathrm{nM}\right)$ in a structure-independent manner (i.e., a junction with dsDNA is not required). Consequently, the simplest mechanism for BRCA2 function is that it delivers its cargo of bound RAD51 molecules to the ssDNA by virtue of high affinity for ssDNA and its capacity to displace the resident RPA. The mechanism is more sophisticated, however. The BRC repeats are not identical in both sequence and function, and they are partitioned with BRC1, 2, 3, and 4 binding free RAD51 tightly, whereas BRC5, 6, 7, and 8 preferentially bind to RAD51 that is bound to ssDNA (Carreira et al. 2009; Carreira and Kowalczykowski 2011). Furthermore, BRC repeats 1-4 block ATP hydrolysis by RAD51, which prevents RAD51dissociation from ssDNA and also keeps RAD51 in the active ATP-bound structural form. This partitioning of labor suggests a mechanism wherein BRCA2 delivers four molecules of RAD51 to the ssDNA to serve as the nucleus to initiate assembly, and then the next four BRC repeats stabilize the next four molecules of RAD51 as they bind to ssDNA on addition to the nucleus. In this way, BRCA2 can chaperone nascent filament assembly of up to eight RAD51 monomers, which would comprise slightly more than one complete turn of the filament (about six monomers).

Despite the suggestive functional analogies to the yeast homolog, human RAD52 is not a mediator in the sense that it does not assist assembly of RAD51 onto RPA-ssDNA (Jensen et al. 2010); BRCA2 fulfills this role. However, in the absence of RPA, RAD52 does stimulate DNA strand exchange by RAD51 when the concentration of RAD51 is substoichiometric rela- 
S.C. Kowalczykowski

tive to the ssDNA (Benson et al. 1998). The mechanism is not completely clear, but it may be caused by recruitment of RAD51 by RAD52, conditioning of the filament, or by simply titrating out the excess ssDNA. However, yeast Rad52 manifests a similar behavior in the absence of RPA; this second role was proposed to arise from stabilization of the Rad51 presynaptic filament by species-specific interaction with Rad52 (New and Kowalczykowski 2002).

The RAD51 paralogs were initially identified by searching cDNA sequence databases for genes with similarity to RAD51 (see, e.g., Albala et al. 1997) or as genes that complemented the X-ray sensitivity of specific cultured hamster cell lines ("X-ray repair cross complementing"; see, e.g., Cartwright et al. 1998; Liu et al. 1998). Subsequently, it was discovered that mutation of these genes conferred genome instability, sensitivity to DNA damaging agents, and recombination defects. These proteins form at least four distinct of heterodimeric and heterotetrameric complexes, including RAD51BRAD51C, RAD51D-XRCC2, RAD51C-XRCC3, and RAD51B-RAD51C-RAD51D-XRCC2 (Masson et al. 2001a,b; Sigurdsson et al. 2001). Adding to this complexity are the proteins SWS1, an ortholog of a component of the yeast Shu complex protein, and SWSAP1, a protein that interacts with SWS1 and has a predicted RecA-core (Martin et al. 2006; Liu et al. 2011b). SWS1 also binds to RAD51D. In addition, SWSAP1 interacts with RAD51 and also with all of the RAD51 paralogs, except XRCC2, leading to a multitude of possible cocomplexes. The SWS1-SWSAP1 complex, like most of the paralog subcomplexes, binds to ssDNA and is a weak ATPase. The proteins are not expressed abundantly in cells, and they are poorly behaved in vitro. For these reasons, understanding their biological and biochemical behaviors has been challenging. However, the finding that the phenotypes of cells deficient in RAD51B, RAD51C, RAD51D, XRCC2, or XRCC3 can be partially suppressed by overexpression of RAD51, just as seen for RecFOR mutants in bacteria and for Rad55Rad57 mutants in yeast, gives support to the notion that the paralogs are mediators, or that they stabilize the Rad51 filament (Takata et al.
2001). A study on RAD51B-RAD51C showed their capacity to partially alleviate the inhibition imposed by RPA on the assembly and function of the RAD51 filament (Sigurdsson et al. 2001). Highlighting the importance to chromosome maintenance and the connection to BRCA2, RAD51B, RAD51C, and RAD51D are known tumor suppressors linked to breast and ovarian cancer (Meindl et al. 2010; Somyajit et al. 2010; Loveday et al. 2011; Orr et al. 2012).

Given the existence of motor proteins in bacteria and yeast that disassemble presynaptic filaments, analogs should exist in humans. However, human cells do not have an identified ortholog of UvrD/Srs2, although they do have orthologs of the other regulatory helicases. In fact, there is a surfeit of helicases that can dissociate RAD51-ssDNA filaments: BLM, RECQ5, FANCJ, and FBH1 (Bugreev et al. 2007b; Hu et al. 2007; Fugger et al. 2009; Sommers et al. 2009; Simandlova et al. 2013). Which protein is most important, how these are targeted, and whether they are blocked by any of the RAD51 paralogs or their associated proteins remains to be determined. Although there is no identified ortholog of Srs2 in humans, human FBH1 can suppress some defects of S. cerevisiae Srs2, implicating it as a functional analog of Srs2/UvrD (Chiolo et al. 2007). Although not present in budding yeast, it is found in Schizosaccharomyces pombe and vertebrates (Kim et al. 2002). So, perhaps FBH1 has assumed the functions of Srs2/UvrD in human cells. FBH1 is a member of the UvrD-like SF1 helicases and it can strip RAD51 from ssDNA (Wu and Hickson 2006; Simandlova et al. 2013). In addition, both BLM and RECQ5 interact with RAD51, suggesting possible recruitment of the helicase to RAD51, or vice versa (Wu et al. 2001; Schwendener et al. 2010). The RAD51D-XRCC2 complex does interact with BLM, but rather than inhibit, it stimulates the unwinding of a fourway junction by BLM (Braybrooke et al. 2003).

PALB2 is another tumor suppressor gene that interacts with BRCA1 and BRCA2 (Xia et al. 2006; Rahman et al. 2007; Reid et al. 2007; Zhang et al. 2009). PALB2 binds to DNA, preferring D-loop structures; it interacts with RAD51; and it stimulates joint molecule 
formation by RAD51 (Buisson et al. 2010; Dray et al. 2010). Its action is cooperative with another protein that interacts with RAD51, RAD51AP1, and stimulation is not at the presynaptic step but rather at the synaptic step by promoting an interaction with the dsDNA target and potentially stabilizing the D-loop (Dray et al. 2010). In another report, PALB2 is found to act synergistically with a truncated "piccolo" BRCA2 construct, but the basis for stimulation of RAD51 was different, resulting from alleviation of inhibition by RPA and stabilization of the filament (Buisson et al. 2010).

Another stimulatory protein in humans and other mammals is the SWI5-SFR1 complex (Akamatsu and Jasin 2010). This complex is the ortholog of S. pombe Swi5-Sfr1 complex and $S$. cerevisiae Sae3-Mei5 complex, which functions only during meiosis in the budding yeast (Akamatsu and Jasin 2010; Yuan and Chen 2011). Knockdown of either component resulted in DNA-damage sensitivity, reduced RAD51 focus formation, and impaired recombination. SWI5-SFR1 interacts with RAD51, stabilizes the RAD51 filament, and stimulates DNA pairing (Yuan and Chen 2011; Tsai et al. 2012). Furthermore, SWI5-SFR1 increases the release of ADP from the RAD51 filament, preventing accumulation of the inactive ADP-form (Su et al. 2014). This is an intriguing mechanism for enhancement of RAD51 function that had originally been ascribed to XRCC2 (Shim et al. 2004). It remains to be determined how this function is distributed between these proteins, and the magnitude of the enhancement attributable to nucleotide exchange.

Humans also have two RAD54 homologs, RAD54 and RAD54B (Hiramoto et al. 1999). Both proteins associate with RAD51, and RAD54 stimulates DNA pairing by RAD51 (Tanaka et al. 2002; Mazina and Mazin 2004). RAD54 introduces topological changes to duplex DNA, but whether the human RAD54 proteins stabilize the RAD51 complex is unknown (Ristic et al. 2001).

Finally, as mentioned earlier, humans have an apparent functional analog of RecX, which is PARI (Moldovan et al. 2012). PARI resembles a domain of UvrD, but lacks the Walker A and B motifs so it does not hydrolyze ATP. PARI interacts stoichiometrically with RAD51 and results in disassembly of RAD51-ssDNA filaments when they are hydrolyzing ATP. It is unclear whether PARI destabilizes the filament, or blocks its reassembly after dissociation, which is the mechanism by which the BRC repeats contribute to the dissociation of RA51-dsDNA complexes (Carreira et al. 2009). In vivo, PARI reduces recombinational DNA repair and its knockdown results in hyperrecombination. Consequently, like RecX, PARI is a physiological modulator of RAD51 function.

\section{REGULATION OF DNA PAIRING BY DNA MOTOR PROTEINS}

The preceding section gave examples of control at the level of presynaptic filament formation. A second level of control is at the level of the joint molecule, either extending the length of the heteroduplex joint by three-strand or four-strand DNA branch migration, or by disrupting the joint molecule to reverse the paired DNA intermediate. The control of filament formation has essentially a yes/no decision with regards to recombination. However, control exerted at the level of joint molecules has several possible complex outcomes: disruption of a joint molecule that had not been replicated aborts recombination; disruption of a joint molecule that had been replicated can lead to recombination DNA repair by SSA or SDSA; and extension of a joint molecule can stabilize the nascent joint molecule and lead to $\mathrm{HJ}$ or $\mathrm{dHJ}$ formation. The role of motor proteins in determining the fate of nascent joint molecules will be summarized (for a more extensive elaboration, see Heyer 2015 and Daley et al. 2014b).

\section{Bacteria}

Several proteins in E. coli recognize joint molecules or Holliday junctions (Bizard and Hickson 2014; Wyatt and West 2014). RecQ, in addition to its role in initiation, can disrupt joint molecules that were made by RecA by unwinding the nascent pairing product (Harmon and Kowalczykowski 1998). This activity requires its motor function, and is consistent with its 
S.C. Kowalczykowski

known in vivo function of disrupting aberrant intermediates that give rise to illegitimate recombination events (Hanada et al. 1997). Likewise, UvrD will also disrupt nascent D-loops produced by RecA, but it can also complete DNA strand exchange, via branch migration, for joint molecules that have progressed beyond a certain size (Morel et al. 1993). These activities likely represent the capacity of $\mathrm{UvrD}$ to bind either the invading strand or the displaced strand and unwind the heteroduplex or duplex DNA, respectively.

The branch migration of HJs is likely promoted primarily by the RuvAB complex (Iwasaki et al. 1992; Tsaneva et al. 1992). The structure of RuvAB complex reveals a beautiful combination of four-way junction recognition by RuvA tetramer and the motor, or pump, activity of the RuvB hexamers (Rafferty et al. 1996; Yamada et al. 2002). Migration of a HJ proceeds at up to $\sim 50-100 \mathrm{bp} / \mathrm{sec}$, for distances of $\sim 7 \mathrm{kbp}$ (Amit et al. 2004; Dawid et al. 2004). RecG can also migrate HJs, either in the direction of RecA-promoted heteroduplex extension or in the opposite (or reverse) directions (Whitby et al. 1993); it can also disrupt protein-free Dloops and R-loops (McGlynn et al. 1997). The current view is that the primary function of RecG is to promote reverse branch migration, or regression specifically from a stalled replication fork, to form HJs that can be used in a number of different pathways to restart replication (Syeda et al. 2014).

\section{Yeast}

In S. cerevisiae, Srs2 unwinds three-stranded structures that resemble D-loops, as was observed for bacterial UvrD, and Rad51 stimulates DNA unwinding by Srs2 (Dupaigne et al. 2008); the overexpression of Srs2 nearly eliminates crossover recombinants, which supports the biochemical observations (Ira et al. 2003). In addition, Mph1, which is also a $3^{\prime} \rightarrow 5^{\prime}$ DNA helicase, disrupts joint molecules that were made with Rad51 (Prakash et al. 2005; Prakash et al. 2009) and will promote three- and fourstranded branch migration (Zheng et al. 2011). Sgs 1 will also disrupt D-loops devoid of protein, but not D-loops formed with Rad51 (Fasching et al. 2015). However, in addition, in the presence of Top3, Sgs1 will promote a novel "D-loop dissolution" reaction to disrupt the paired three-stranded DNA complexes in a process that requires a species-specific recruitment of Sgs1-Top3 by Rad51; this reaction has molecular parallels to $\mathrm{dHJ}$ dissolution discussed below. Finally, Rad54 can dissociate Rad51 from a Dloop to strip it clean in preparation for DNA synthesis and, paradoxically, even disrupt the D-loops (Solinger et al. 2002; Bugreev et al. 2007a; Li and Heyer 2009). Interestingly, however, with longer DNA substrates, Rad54 acts as a "heteroduplex pump" to stabilize and extend nascent joint molecules made by Rad51 (Wright and Heyer 2014).

Rad54 will also drive four-strand DNA heteroduplex extension due it high affinity for a four-way junction having one ssDNA arm (Solinger and Heyer 2001; Bugreev et al. 2006). Rad51 stimulates this branch migration capacity of Rad54 (Rossi and Mazin 2008). Like Rad54, Rdh54 can also use its dsDNA translocation capacity to disrupt joint molecules that it has encountered on the duplex DNA track (Nimonkar et al. 2007), but presumably when properly targeted by Rad51 or Dmc1, the motor activity will result in productive heteroduplex extension.

Genetic analysis of plasmid DNA gap repair showed that $\sim 90 \%$ of recombination events do not lead to crossover formation. Sgs1, Mph1, and Srs2 contributed to formation of noncrossover products by promoting SDSA via D-loop disruption (Mitchel et al. 2013). In wild-type cells, Mph1 was inferred to be the primary helicase that disrupted D-loop intermediates although, in its absence, Sgs1 and Srs2 could participate. In addition, Sgs1 acted in dissolution of dHJs, and Srs2 was proposed to also dismantle nicked HJs (Mitchel et al. 2013).

\section{Human}

Human cells have several orthologs of the regulatory helicases. Of the five RecQ-helicases, BLM, WRN, and RECQ1 will disrupt proteinfree D-loops. As for Sgs1, BLM disrupts joint molecules made by RecA or devoid of RAD51 
(Bachrati et al. 2006; Bugreev et al. 2007b; Popuri et al. 2008), but not when RAD51 is active and bound to the D-loop (Nimonkar et al. 2008). Similarly, WRN can disrupt naked Dloops (Orren et al. 2002; Opresko et al. 2009), as can RECQ1 (Popuri et al. 2008; Mazina et al. 2012); their activity on D-loops with RAD51 present was not tested. The inability of BLM to disrupt joint molecules bound by RAD51 may suggest that other helicases, such as FANCM, are responsible for dealing with human RAD51-bound structure, or that RAD51 is first removed by RAD54.

In contrast to the DNA helicases, however, the dsDNA translocases RAD54, SMARCAL1, and ZRANB can disrupt D-loops made either with or without RAD51 because of their capacity to translocate on dsDNA and to branch migrate the homologously paired or branched structures that they might encounter (Bugreev et al. 2006, 2007a; Betous et al. 2012, 2013; Ciccia et al. 2012). These proteins branch migrate various three- and four-way junctions. SMARCAL1 behaves similarly to bacterial RecG, and it was recently suggested that these two proteins are functional analogs (Betous et al. 2013).

In addition to these dsDNA translocases, several helicases can branch migrate four-way junctions. BLM can specifically bind a $\mathrm{HJ}$ and migrate it several kbp (Karow et al. 2000). RECQ1 is another helicase that has the capacity to migrate both three- and four-stranded intermediates for at least several hundred base pairs (Bugreev et al. 2008; Mazina et al. 2012). FANCM is yet another helicase that binds to HJs with both high specificity and affinity (subnanomolar); it also promotes branch migration of HJs over distances of up to $2.6 \mathrm{kbp}$ (Gari et al. 2008). The capacity of BLM to specifically migrate HJs parallels the behavior of Sgs1 and it is needed for the dissolution process described below.

\section{DISSOLUTION AND RESOLUTION OF SINGLE AND DOUBLE HOLLIDAY JUNCTIONS}

In 1964, the four-way junction that joins two DNA duplexes was proposed as the structure for an intermediate of genetic recombination (Holliday 1964). The prescience of this proposal and the utility of the structure have established the Holliday junction as dogma in the recombination field. When the two joined DNA duplexes are fully homologous, this four-way junction can branch migrate, resulting in the genetically verified tracts of heteroduplex DNA. Branch migration can random, driven by thermal energy, or it can be directional, catalyzed by a motor protein.

To separate the two DNA molecules, at least transient endonucleolytic cleavage is required. Separation was initially was proposed to involve symmetric cleavage and was envisioned to occur by a nuclease that was "smart" enough to cut across the junction and, ideally, to not cutoff one arm. Furthermore, many models of recombination proposed two HJs; largely for expedience, it was proposed that each could be cleaved independently. However, it was subsequently recognized that parental duplexes joined by a $\mathrm{dHJ}$ possessed a unique attribute that was absent in duplexes joined by a single HJ: namely, the intermediate with a $\mathrm{dHJ}$ represents two topologically linked duplex DNA molecules (a multiply linked hemicatenane). This realization meant that, in principle, the two chromosomes could be separated by transiently passing single strands of DNA through each of the intertwined parental duplexes to unlink them and with the concomitant movement of one junction toward the other (Nasmyth 1982; Wang et al. 1990). This process was envisioned to require a type IA topoisomerase, perhaps assisted by a motor protein to move the $\mathrm{HJ}$ and/or to produce ssDNA for the topoisomerase. Such a separation was elegantly shown using BLM and topoisomerase III $\alpha$ (Topo III $\alpha$ ), in a process now called "dissolution" to distinguish it from nucleolytic "resolution" (Wu and Hickson 2003). These processes are comprehensively addressed elsewhere (Bizard and Hickson 2014; Wyatt and West 2014).

The interesting feature of these two very different reactions is that symmetric cleavage by a nuclease produces a 50:50 mixture of crossover and noncrossover recombinants, whereas dissolution leads to only noncrossovers. Biologically, 
S.C. Kowalczykowski

this is an important distinction because crossovers at nonallelic sites can cause chromosomal translocations, and crossovers between homologs can lead to loss of heterozygosity (LOH), a phenotype commonly associated with cancer progression. For bacteria, a single crossover (or any odd number) between circular chromosomes produces a dimeric circular chromosome that cannot partition into daughter cells on cell division.

\section{Bacteria}

The RuvAB complex, introduced earlier, is a specialized DNA motor complex that binds to a HJ, and extends the DNA heteroduplex by migrating the crossover point. The RuvAB complex functions with RuvC, which is the prototypic endonuclease that recognizes and cleaves a $\mathrm{HJ}$ to introduce concerted cuts across the junction (Bennett et al. 1993; Eggleston and West 2000; Wyatt and West 2014). RuvC functions as a dimer, and it has a 1000- to 10,000-fold affinity for HJs over dsDNA (West 1997). Cleavage occurs preferentially at $5^{\prime}-(\mathrm{A} / \mathrm{T}) \mathrm{TT}(\mathrm{G} /$ C) $-3^{\prime}$ and is precisely symmetrical in that the product molecules can be religated. Resolution depends on homology at the junction and is unbiased on naked HJs, but is biased toward crossover recombinants (3:1) when RecA is present.

E. coli possesses orthologs of BLM and Topo III $\alpha$, RecQ and topoisomerase III (Topo III). Topo III is a type IA topoisomerase that passes one strand of DNA through another (Wang et al. 1990). RecQ helicase specifically stimulates the activity of Topo III to catenate and decatenate dsDNA by catalyzing a series of ssDNA passes (Harmon et al. 1999, 2003). In a manner analogous to the eukaryotic counterparts (Cejka et al. 2010b; Bocquet et al. 2014), RecQ and Topo III will also dissolve a $\mathrm{dHJ}$ (K Morimatsu and SC Kowalczykowski, unpubl.).

\section{Yeast}

The search for eukaryotic HJ resolution enzymes encountered many proverbial "forks in the road." Apart from the mitochondrial en- zyme, CCE1, the first protein reported to cleave HJs was Mus81-Mms4 (Mus81-Eme1 in S. pombe) (Boddy et al. 2001). Mus81 is a member of the XPF-family of nuclease and it was discovered by virtue of its interactions with the checkpoint kinase, Cds1, in S. pombe and with Rad54 in S. cerevisiae (Boddy et al. 2000; Interthal and Heyer 2000). Although the protein from extracts and pull-down fractions could cleave HJs (Boddy et al. 2001), the purified protein cleaved only nicked HJs or a variety of flexible DNA structures with ssDNA character (Ehmsen and Heyer 2008). In addition, unless a nicked HJ was used, the cleavage products were not perfectly symmetrical, because the cleavage products could not be religated. These finding led to the nonexclusive ideas that a component or modification is missing from the Mus81Mms4/Eme1 reactions, a nicked $\mathrm{HJ}$ is the actual biological intermediate, or another factor cleaves intact HJs. A possible resolution to this discrepancy was identified when it was discovered in S. pombe that phosphorylation, dependent on Cdc2 (CDK1) and Rad3 (ATR), activated Mus81-Emel to cleave HJs (Dehe et al. 2013). Interestingly, the interaction with Rad54 stimulates Mus81 and may help target it to HJs (Matulova et al. 2009).

In addition to Mus81-Mms4, there are several other nucleases including Slx1 and Slx4, which form a co-complex (Fricke and Brill 2003; Ashton et al. 2011; Schwartz et al. 2012). In mammals, Slx1-Slx4 interacts with Mus81Mms4, but not in S. cerevisiae. Both Mus81Mms4 and Slx1-Slx4 are structure-selective nucleases that cleave many branched structures including nicked HJs. In general, the products of these reactions are not ligatable, implying asymmetric cutting, further emphasizing the distinction between the prokaryotic and eukaryotic nucleases. Yet another nuclease capable of $\mathrm{HJ}$ cleavage is Yen1, a member of the Rad2-family of nucleases (Ip et al. 2008). Notably, purified Yen1 dimerizes and cleaves intact HJs by introducing two concerted cuts and the cleavage is largely symmetric. Although it cleaves intact HJs, its specificity and that of its human homolog, GEN1, is not high as it cleaves other DNA structures including three-way junctions (Ip 
et al. 2008). One notable characteristic of Yen1 is that it is not always located in the nucleus: throughout $\mathrm{S}$ phase, phosphorylation by Cdk inactivates its catalytic activity and prevents nuclear import; however, at anaphase, Cdc14 phosphatase activity permits nuclear entry and activates cleavage function (Blanco et al. 2014; Eissler et al. 2014). Yen1 is not essential, and its need is revealed only in cells lacking Mus81Mms4, suggesting that the intermediate and HJ structures normally processed by Mus81Mms4 accumulate to a level where their cleavage by Yen 1 becomes essential (Ho et al. 2010; Mazon and Symington 2013). Collectively, these findings suggest that Mus81-Mms4 and Slx1Slx 4 act on HJs, nicked HJ, and joint molecules, throughout $S$ phase; at anaphase, any uncleaved recombination or replication intermediates are cleaved by the activated Yen 1 .

S. cerevisiae has orthologs of BLM-TopIII $\alpha$, Sgs1-Top3. Sgs1-Top3 also interacts with Rmi1 via Top3 (Chang et al. 2005; Mullen et al. 2005; Chen and Brill 2007). Sgs 1 shows a marked preference for binding to and unwinding HJs (Cejka and Kowalczykowski 2010). The Sgs1-Top3Rmilcomplex promotes $\mathrm{dHJ}$ dissolution, with Rmil playing an important role in decatenation of the dHJ (Cejka et al. 2010b). This reaction is most efficient when the cognate ssDNA-binding protein is present, because of a species-specific role for RPA in Sgs1-dependent DNA unwinding. Genetic observations show that Sgs1Top3-Rmil function to directly dissolve about one-half to two-thirds of $\mathrm{dHJ}$ intermediate, ensuring that these repair events will not result in crossovers (Ira et al. 2003; Mitchel et al. 2013; Mehta and Haber 2014).

\section{Human}

In parallel with the work in S. pombe, MUS81 was identified as a $\mathrm{HJ}$ cutting enzyme in human cells (Chen et al. 2001). It is structure-selective, and the enzyme from pull-downs can cleave HJs. MUS81 shares many of the same general properties as the yeast enzymes, including interaction with an EME1 ortholog (Ciccia et al. 2003; Ogrunc and Sancar 2003). MUS81EME1 also interacts specifically with RAD54 and is stimulated by this interaction, suggesting both targeting to HJs and cooperation in their processing (Mazina and Mazin 2008). There is a second EME1 homolog, EME2; the purified MUS81-EME2 complex is also a structure selective nuclease that cleaves intact HJs, as well as nicked HJs and other intermediates (Amangyeld et al. 2014; Pepe and West 2014). Humans also have orthologs of SLX1-SLX4, which were also found to cleave HJs, albeit in two separate nicking events (Fekairi et al. 2009; Svendsen et al. 2009; Wyatt et al. 2013). SLX1-SLX4 binds MUS81-EME1 and cleavage by this heterotetrameric complex is more effective than by either complex alone and the products are symmetric (Wyatt et al. 2013). Similarly, humans have an ortholog of Yen1, called GEN1 (Ip et al. 2008). Like Yen1, GEN1 will cleave a variety of branched DNA molecules. Holliday junction cleavage was only 7 - and 20-fold greater than that observed with $5^{\prime}$-flap or replication fork substrates, respectively, but cutting was concerted because of dimerization of GEN1 and 55\% of the products were ligatable (Ip et al. 2008; Rass et al. 2010; Wyatt et al. 2013). For comparison, equivalent reactions with SLX1-SLX4 produce $16 \%$ ligatable product, and those with MUS81EME1 only 2\% (Wyatt et al. 2013). However, like Yen 1, GEN1 is not in the nucleus during $S$ phase, and only after breakdown of the nuclear envelop is GEN1 introduced to DNA (Chan and West 2014). Given its broad substrate specificity and, that in its absence, there is an abundance of anaphase bridges, GEN1 plays an important function as a debranching enzyme to remove unprocessed $\mathrm{HJ}$ s and the Y-forks that remain after unfinished recombination and replication, allowing chromosomal segregation. Clearly, resolution of the manner(s) and mechanism(s) by which HJs are resolved is ongoing.

Dissolution of dHJs was first discovered using the human BLM helicase and Topo III $\alpha$. A clever model substrate made from oligonucleotide substrates, with a linking number of $1-2$ was initially used to show that this complex could separate and unlink the DNA molecules topologically (Wu and Hickson 2003). Subsequently, it was shown that RMI1 stimulated dissolution (Raynard et al. 2006; Wu et al. 
2006a). RMI1 (BLAP75) is a largely conserved protein that interacts with TOPO III $\alpha$ (Yin et al. 2005; Bocquet et al. 2014). Subsequently, RMI2 (BLAP18) was discovered as another component that further stimulated $\mathrm{dHJ}$ dissolution (Singh et al. 2008; Xu et al. 2008). Therefore, the mechanim of dissolution is highly conserved, and offers an elegant way to separate recombination products without the potential for a crossover between the parental participants.

\section{CONCLUDING REMARKS}

So much is known, yet so much remains to be learned. The understanding of recombination has developed remarkably from the pioneering cytological and genetic analyses, and current studies continue to increase in sophistication. There is no doubt that additional proteins that control or effect recombinational DNA repair will be uncovered, especially in mammals. The role of posttranslational modifications was hardly mentioned in this review. Nonetheless, control via phosphorylation is well documented and, no doubt, will continue to become better appreciated. In addition, regulation through sumoylation and ubiquitylation represents yet another combinatorial challenge and frontier. The last few decades have seen the growing realization that recombination intersects with all aspects of DNA metabolism including other types of DNA repair, replication, and transcription. Research at these interfaces will continue to yield a better-integrated picture of the role of recombination in cellular function. The next generation of research will see greater integration of these once disparate areas, as well as the continued convergence of methods from chemistry, synthetic biology, systems biology, and physics. Without doubt, such convergence will not only provides new knowledge about these processes, but also will have great impact on human health, especially for diseases with close links to recombination, such as cancer and Fanconi anemia. The now full appreciation that recombination in $E$. coli is fundamentally the same as in Elephas maximus, means that an understanding of recombination in all organisms will inform application of established concepts such as synthetic lethality to treatments of human disease, which was so successfully shown for PARP (poly[ADP-ribose] polymerase) inhibitors, as well as facilitate identification of new targets and new therapeutics. Last but not least, I fully expect that new fully unexpected things will continue to be learned.

\section{ACKNOWLEDGMENTS}

The research in my laboratory is supported by grants from the National Institutes of Health, GM41347, GM62653, GM64745, and CA154920, and from the Department of Defense, CDMRP, Breast Cancer Research Program, W81XWH-13-1-0322. I am grateful to the members of my laboratory for their careful reading of a draft, and to Wolf Heyer and Neil Hunter for comments and ongoing discussions going back at least a decade when we started teaching our graduate level course on the subjects contained within our contributions to this series.

\section{REFERENCES}

${ }^{*}$ Reference is also in this collection.

Aboussekhra A, Chanet R, Adjiri A, Fabre F. 1992. Semidominant suppressors of Srs2 helicase mutations of Saccharomyces cerevisiae map in the RAD51 gene, whose sequence predicts a protein with similarities to procaryotic RecA proteins. Mol Cell Biol 12: 3224-3234.

* Aguilera A, Gaillard H. 2014. Transcription and recombination: When RNA meets DNA. Cold Spring Harb Perspect Biol 6: a016543.

Akamatsu Y, Jasin M. 2010. Role for the mammalian Swi5Sfr1 complex in DNA strand break repair through homologous recombination. PLoS Genet 6: e1001160.

Albala JS, Thelen MP, Prange C, Fan W, Christensen M, Thompson LH, Lennon GG. 1997. Identification of a novel human RAD51 homolog, RAD51B. Genomics 46: 476-479.

Amangyeld T, Shin YK, Lee M, Kwon B, Seo YS. 2014. Human MUS81-EME2 can cleave a variety of DNA structures including intact Holliday junction and nicked duplex. Nucleic Acids Res 42: 5846-5862.

Amit R, Gileadi O, Stavans J. 2004. Direct observation of RuvAB-catalyzed branch migration of single Holliday junctions. Proc Natl Acad Sci 101: 11605-11610.

Amitani I, Baskin RJ, Kowalczykowski SC. 2006. Visualization of Rad54, a chromatin remodeling protein, translocating on single DNA molecules. Mol Cell 23: 143-148.

Anderson DG, Kowalczykowski SC. 1997a. The recombination hot spot $\chi$ is a regulatory element that switches the 
polarity of DNA degradation by the RecBCD enzyme. Genes Dev 11: 571-581.

Anderson DG, Kowalczykowski SC. 1997b. The translocating RecBCD enzyme stimulates recombination by directing RecA protein onto ssDNA in a $\chi$-regulated manner. Cell 90: 77-86.

Arnold DA, Kowalczykowski SC. 2000. Facilitated loading of RecA protein is essential to recombination by RecBCD enzyme. J Biol Chem 275: 12261-12265.

Asai T, Bates DB, Kogoma T. 1994. DNA replication triggered by double-stranded breaks in E. coli: Dependence on homologous recombination functions. Cell 78: 10511061.

Ashton TM, Mankouri HW, Heidenblut A, McHugh PJ, Hickson ID. 2011. Pathways for Holliday junction processing during homologous recombination in Saccharomyces cerevisiae. Mol Cell Biol 31: 1921-1933.

Bachrati CZ, Borts RH, Hickson ID. 2006. Mobile D-loops are a preferred substrate for the Bloom's syndrome helicase. Nucleic Acids Res 34: 2269-2279.

Bae SH, Choi E, Lee KH, Park JS, Lee SH, Seo YS. 1998. Dna2 of Saccharomyces cerevisiae possesses a singlestranded DNA-specific endonuclease activity that is able to act on double-stranded DNA in the presence of ATP. J Biol Chem 273: 26880-26890.

Bae SH, Bae KH, Kim JA, Seo YS. 2001. RPA governs endonuclease switching during processing of Okazaki fragments in eukaryotes. Nature 412: 456-461.

Bai Y, Symington LS. 1996. A Rad52 homolog is required for RAD51-independent mitotic recombination in Saccharomyces cerevisiae. Genes Dev 10: 2025-2037.

Baumann P, West SC. 1997. The human Rad51 protein: Polarity of strand transfer and stimulation by hRP-A. EMBO J 16: 5198-5206.

Baumann P, Benson FE, West SC. 1996. Human Rad51 protein promotes ATP-dependent homologous pairing and strand transfer reactions in vitro. Cell 87: 757-766.

Bell JC, Plank JL, Dombrowski CC, Kowalczykowski SC 2012. Direct imaging of RecA nucleation and growth on single molecules of SSB-coated ssDNA. Nature 491: 274-278.

Bennett RJ, Dunderdale HJ, West SC. 1993. Resolution of Holliday junctions by RuvC resolvase: Cleavage specificity and DNA distortion. Cell 74: 1021-1031.

Benson FE, Baumann P, West SC. 1998. Synergistic actions of Rad51 and Rad52 in recombination and DNA repair. Nature 391: 401-404.

Bertucat G, Lavery R, Prévost C. 1998. A model for parallel triple helix formation by RecA: Single-single association with a homologous duplex via the minor groove. J Biomol Struct Dyn 16: $535-546$.

Betous R, Mason AC, Rambo RP, Bansbach CE, Badu-Nkansah A, Sirbu BM, Eichman BF, Cortez D. 2012. SMARCAL1 catalyzes fork regression and Holliday junction migration to maintain genome stability during DNA replication. Genes Dev 26: 151-162.

Betous R, Couch FB, Mason AC, Eichman BF, Manosas M, Cortez D. 2013. Substrate-selective repair and restart of replication forks by DNA translocases. Cell Rep 3: 19581969.
Bianco PR, Kowalczykowski SC. 1997. The recombination hotspot $\chi$ is recognized by the translocating RecBCD enzyme as the single strand of DNA containing the sequence 5'-GCTGGTGG-3'. Proc Natl Acad Sci 94: 67066711.

Bianco PR, Tracy RB, Kowalczykowski SC. 1998. DNA strand exchange proteins: A biochemical and physical comparison. Front Biosci 3: D570-603.

Bianco PR, Brewer LR, Corzett M, Balhorn R, Yeh Y, Kowalczykowski SC, Baskin RJ. 2001. Processive translocation and DNA unwinding by individual RecBCD enzyme molecules. Nature 409: 374-378.

* Bizard AH, Hickson ID. 2014. The dissolution of double Holliday junctions. Cold Spring Harb Perspect Biol 6: a016477.

Blanco MG, Matos J, West SC. 2014. Dual control of Yen1 nuclease activity and cellular localization by $\mathrm{Cdk}$ and Cdc14 prevents genome instability. Mol Cell 54: 94-106.

Bocquet N, Bizard AH, Abdulrahman W, Larsen NB, Faty M, Cavadini S, Bunker RD, Kowalczykowski SC, Cejka P, Hickson ID, et al. 2014. Structural and mechanistic insight into Holliday-junction dissolution by topoisomerase III $\alpha$ and RMI1. Nat Struct Mol Biol 21: 261-268.

Boddy MN, Lopez-Girona A, Shanahan P, Interthal H, Heyer WD, Russell P. 2000. Damage tolerance protein Mus81 associates with the FHA1 domain of checkpoint kinase Cds1. Mol Cell Biol 20: 8758-8766.

Boddy MN, Gaillard PH, McDonald WH, Shanahan P, Yates JR III, Russell P. 2001. Mus81-Eme1 are essential components of a Holliday junction resolvase. Cell 107: $537-$ 548.

Bothmer A, Robbiani DF, Feldhahn N, Gazumyan A, Nussenzweig A, Nussenzweig MC. 2010. 53BP1 regulates DNA resection and the choice between classical and alternative end joining during class switch recombination. $J$ Exp Med 207: 855-865.

Braybrooke JP, Li JL, Wu L, Caple F, Benson FE, Hickson ID. 2003. Functional interaction between the Bloom's syndrome helicase and the RAD51 paralog, RAD51L3 (RAD51D). J Biol Chem 278: 48357-48366.

Brosh RM Jr, 2013. DNA helicases involved in DNA repair and their roles in cancer. Nat Rev Cancer 13: 542-558.

* Brown MS, Bishop DK. 2015. DNA strand exchange and RecA homologs in meiosis. Cold Spring Harb Perspect Biol 7: a016659.

Budd ME, Choe W, Campbell JL. 2000. The nuclease activity of the yeast DNA2 protein, which is related to the RecBlike nucleases, is essential in vivo. J Biol Chem 275: 16518-16529.

Bugreev DV, Mazina OM, Mazin AV. 2006. Rad54 protein promotes branch migration of Holliday junctions. $\mathrm{Na}$ ture 442: 590-593.

Bugreev DV, Hanaoka F, Mazin AV. 2007a. Rad54 dissociates homologous recombination intermediates by branch migration. Nat Struct Mol Biol 14: 746-753.

Bugreev DV, Yu X, Egelman EH, Mazin AV. 2007b. Novel pro- and anti-recombination activities of the Bloom's syndrome helicase. Genes Dev 21: 3085-3094.

Bugreev DV, Brosh RM Jr, Mazin AV. 2008. RECQ1 possesses DNA branch migration activity. J Biol Chem 283: 20231 20242. 
S.C. Kowalczykowski

Buisson R, Dion-Cote AM, Coulombe Y, Launay H, Cai H, Stasiak AZ, Stasiak A, Xia B, Masson JY. 2010. Cooperation of breast cancer proteins PALB2 and piccolo BRCA2 in stimulating homologous recombination. Nat Struct Mol Biol 17: 1247-1254.

Bunting SF, Callen E, Wong N, Chen HT, Polato F, Gunn A, Bothmer A, Feldhahn N, Fernandez-Capetillo O, Cao L, et al. 2010. 53BP1 inhibits homologous recombination in Brcal-deficient cells by blocking resection of DNA breaks. Cell 141: 243-254.

Candelli A, Holthausen JT, Depken M, Brouwer I, Franker MA, Marchetti M, Heller I, Bernard S, Garcin EB, Modesti M, et al. 2014. Visualization and quantification of nascent RAD51 filament formation at single-monomer resolution. Proc Natl Acad Sci 111: 15090-15095.

Cannavo E, Cejka P. 2014. Sae2 promotes dsDNA endonuclease activity within Mre11-Rad50 - Xrs2 to resect DNA breaks. Nature 514: 122-125.

Cannavo E, Cejka P, Kowalczykowski SC. 2013. Relationship of DNA degradation by Saccharomyces cerevisiae exonuclease 1 and its stimulation by RPA and Mre11-Rad50Xrs2 to DNA end resection. Proc Natl Acad Sci 110: E1661-E1668.

Carreira A, Kowalczykowski SC. 2011. Two classes of BRC repeats in BRCA2 promote RAD51 nucleoprotein filament function by distinct mechanisms. Proc Natl Acad Sci 108: 10448-10453.

Carreira A, Hilario J, Amitani I, Baskin RJ, Shivji MK, Venkitaraman AR, Kowalczykowski SC. 2009. The BRC repeats of BRCA2 modulate the DNA-binding selectivity of RAD51. Cell 136: 1032-1043.

Cartwright R, Tambini CE, Simpson PJ, Thacker J. 1998. The XRCC2 DNA repair gene from human and mouse encodes a novel member of the recA/RAD51 family. $\mathrm{Nu}$ cleic Acids Res 26: 3084-3089.

Cazenave C, Toulme JJ, Helene C. 1983. Binding of RecA protein to single-stranded nucleic acids: spectroscopic studies using fluorescent polynucleotides. $E M B O J \mathbf{2}$ : 2247-2251.

Ceballos SJ, Heyer WD. 2011. Functions of the Snf2/Swi2 family Rad54 motor protein in homologous recombination. Biochim Biophys Acta 1809: 509-523.

Cejka P, Kowalczykowski SC. 2010. The full-length Saccharomyces cerevisiae Sgs 1 protein is a vigorous DNA helicase that preferentially unwinds Holliday junctions. $J$ Biol Chem 285: 8290-8301.

Cejka P, Cannavo E, Polaczek P, Masuda-Sasa T, Pokharel S, Campbell JL, Kowalczykowski SC. 2010a. DNA end resection by Dna2-Sgs1-RPA and its stimulation by Top3-Rmil and Mre11-Rad50-Xrs2. Nature 467: 112-116.

Cejka P, Plank JL, Bachrati CZ, Hickson ID, Kowalczykowski SC. 2010b. Rmil stimulates decatenation of double Holliday junctions during dissolution by Sgs1-Top3. Nat Struct Mol Biol 17: 1377-1382.

Chan YW, West SC. 2014. Spatial control of the GEN1 Holliday junction resolvase ensures genome stability. Nat Commun 5: 4844.

Chanet R, Heude M, Adjiri A, Maloisel L, Fabre F. 1996 Semidominant mutations in the yeast Rad51 protein and their relationships with the Srs2 helicase. Mol Cell Biol 16: 4782-4789.
Chang M, Bellaoui M, Zhang C, Desai R, Morozov P, Delgado-Cruzata L, Rothstein R, Freyer GA, Boone C, Brown GW. 2005. RMI1/NCE4, a suppressor of genome instability, encodes a member of the RecQ helicase/Topo III complex. EMBO J 24: 2024-2033.

Chapman JR, Barral P, Vannier JB, Borel V, Steger M, TomasLoba A, Sartori AA, Adams IR, Batista FD, Boulton SJ. 2013. RIF1 is essential for 53BP1-dependent nonhomologous end joining and suppression of DNA doublestrand break resection. Mol Cell 49: 858-871.

Chédin F, Kowalczykowski SC. 2002. A novel family of regulated helicases/nucleases from Gram-positive bacteria: Insights into the initiation of DNA recombination. Mol Microbiol 43: 823-834.

Chen CF, Brill SJ. 2007. Binding and activation of DNA topoisomerase III by the Rmil subunit. J Biol Chem 282: $28971-28979$.

Chen R, Wold MS. 2014. Replication protein A: singlestranded DNA's first responder: Dynamic DNA-interactions allow replication protein A to direct single-strand DNA intermediates into different pathways for synthesis or repair. Bioessays 36: 1156-1161.

Chen XB, Melchionna R, Denis CM, Gaillard PH, Blasina A, Van de Weyer I, Boddy MN, Russell P, Vialard J, McGowan CH. 2001. Human Mus81-associated endonuclease cleaves Holliday junctions in vitro. Mol Cell 8: $1117-$ 1127.

Chen Z, Yang H, Pavletich NP. 2008. Mechanism of homologous recombination from the RecA-ssDNA/dsDNA structures. Nature 453: 489-494.

Chen X, Cui D, Papusha A, Zhang X, Chu CD, Tang J, Chen K, Pan X, Ira G. 2012. The Fun30 nucleosome remodeller promotes resection of DNA double-strand break ends. Nature 489: 576-580.

Chen H, Lisby M, Symington LS. 2013. RPA coordinates DNA end resection and prevents formation of DNA hairpins. Mol Cell 50: 589-600.

Chi P, Kwon Y, Moses DN, Seong C, Sehorn MG, Singh AK, Tsubouchi H, Greene EC, Klein HL, Sung P. 2009. Functional interactions of meiotic recombination factors Rdh54 and Dmc1. DNA Repair (Amst) 8: 279-284.

Chiolo I, Saponaro M, Baryshnikova A, Kim JH, Seo YS, Liberi G. 2007. The human F-box DNA helicase FBH1 faces Saccharomyces cerevisiae Srs2 and postreplication repair pathway roles. Mol Cell Biol 27: 7439-7450.

Churchill JJ, Kowalczykowski SC. 2000. Identification of the RecA protein-loading domain of RecBCD enzyme. J Mol Biol 297: 537-542.

Churchill JJ, Anderson DG, Kowalczykowski SC. 1999. The RecBC enzyme loads RecA protein onto ssDNA asymmetrically and independently of $\chi$, resulting in constitutive recombination activation. Genes Dev 13: 901-911.

Ciccia A, Constantinou A, West SC. 2003. Identification and characterization of the human mus81-emel endonuclease. J Biol Chem 278: 25172-25178.

Ciccia A, Nimonkar AV, Hu Y, Hajdu I, Achar YJ, Izhar L, Petit SA, Adamson B, Yoon JC, Kowalczykowski SC, et al. 2012. Polyubiquitinated PCNA recruits the ZRANB3 translocase to maintain genomic integrity after replication stress. Mol Cell 47: 396-409. 
Clark AJ. 1973. Recombination deficient mutants of E. coli and other bacteria. Annu Rev Genet 7: 67-86.

Clark AJ, Margulies AD. 1965. Isolation and characterization of recombination-deficient mutants of Escherichia coli K12. Proc Natl Acad Sci 53: 451-459.

Connelly JC, Kirkham LA, Leach DR. 1998. The SbcCD nuclease of Escherichia coli is a structural maintenance of chromosomes (SMC) family protein that cleaves hairpin DNA. Proc Natl Acad Sci 95: 7969-7974.

Costelloe T, Louge R, Tomimatsu N, Mukherjee B, Martini E, Khadaroo B, Dubois K, Wiegant WW, Thierry A, Burma S, et al. 2012. The yeast Fun30 and human SMARCAD1 chromatin remodellers promote DNA end resection. Nature 489: 581-584.

Courcelle J, Hanawalt PC. 1999. RecQ and RecJ process blocked replication forks prior to the resumption of replication in UV-irradiated Escherichia coli. Mol Gen Genet 262: $543-551$.

Cox MM. 2007. Regulation of bacterial RecA protein function. Crit Rev Biochem Mol Biol 42: 41-63.

Cox MM, Soltis DA, Livneh Z, Lehman IR. 1983. On the role of single-stranded DNA binding protein in recA proteinpromoted DNA strand exchange. J Biol Chem 258: 2577 2585.

Daley JM, Chiba T, Xue X, Niu H, Sung P. 2014a. Multifaceted role of the Topo III $\alpha-$ RMI1-RMI2 complex and DNA2 in the BLM-dependent pathway of DNA break end resection. Nucleic Acids Res 42: 11083-11091.

* Daley JM, Gaines WA, Kwon YH, Sung P. 2014b. Regulation of DNA pairing in homologous recombination. Cold Spring Harb Perspect Biol 6: a017954.

Dawid A, Croquette V, Grigoriev M, Heslot F. 2004. Singlemolecule study of RuvAB-mediated Holliday-junction migration. Proc Natl Acad Sci 101: 11611-11616.

Deans AJ, West SC. 2011. DNA interstrand crosslink repair and cancer. Nat Rev Cancer 11: 467-480.

Dehe PM, Coulon S, Scaglione S, Shanahan P, Takedachi A, Wohlschlegel JA, Yates JR III, Llorente B, Russell P, Gaillard PH. 2013. Regulation of Mus81-Eme1 Holliday junction resolvase in response to DNA damage. Nat Struct Mol Biol 20: 598-603.

Dillingham MS, Kowalczykowski SC. 2008. RecBCD enzyme and the repair of double-stranded DNA breaks. Microbiol Mol Biol Rev 72: 642-671.

Dillingham MS, Spies M, Kowalczykowski SC. 2003 RecBCD enzyme is a bipolar DNA helicase. Nature 423: 893-897.

Dillingham MS, Webb MR, Kowalczykowski SC. 2005. Bipolar DNA translocation contributes to highly processive DNA unwinding by RecBCD enzyme. J Biol Chem 280: 37069-37077.

Dion V, Kalck V, Horigome C, Towbin BD, Gasser SM. 2012. Increased mobility of double-strand breaks requires Mec1, Rad9 and the homologous recombination machinery. Nat Cell Biol 14: 502-509.

Dixon DA, Kowalczykowski SC. 1991. Homologous pairing in vitro stimulated by the recombination hotspot, $\chi$. Cell 66: $361-371$.

Dixon DA, Kowalczykowski SC. 1993. The recombination hotspot $\chi$ is a regulatory sequence that acts by attenuating the nuclease activity of the E. coli RecBCD enzyme. Cell 73: 87-96.

Doermann AH, Chase M, Stahl FW. 1955. Genetic recombination and replication in bacteriophage. J Cell Physiol Suppl 45: 51-74.

* Doksani Y, de Lange T. 2014. The role of double-strand break repair pathways at functional and dysfunctional telomeres. Cold Spring Harb Perspect Biol 6: a016576.

Dray E, Etchin J, Wiese C, Saro D, Williams GJ, Hammel M, Yu X, Galkin VE, Liu D, Tsai MS, et al. 2010. Enhancement of RAD51 recombinase activity by the tumor suppressor PALB2. Nat Struct Mol Biol 17: 1255-1259.

Dupaigne P, Le Breton C, Fabre F, Gangloff S, Le Cam E, Veaute X. 2008. The Srs2 helicase activity is stimulated by Rad51 filaments on dsDNA: Implications for crossover incidence during mitotic recombination. Mol Cell 29: 243-254.

Eapen VV, Sugawara N, Tsabar M, Wu WH, Haber JE. 2012. The Saccharomyces cerevisiae chromatin remodeler Fun30 regulates DNA end resection and checkpoint deactivation. Mol Cell Biol 32: 4727-4740.

Eggler AL, Inman RB, Cox MM. 2002. The Rad51-dependent pairing of long DNA substrates is stabilized by replication protein A. J Biol Chem 277: 39280-39288.

Eggleston AK, Kowalczykowski SC. 1991. An overview of homologous pairing and DNA strand exchange proteins. Biochimie 73: 163-176.

Eggleston AK, West SC. 2000. Cleavage of Holliday junctions by the Escherichia coli RuvABC complex. J Biol Chem 275: 26467-26476.

Ehmsen KT, Heyer WD. 2008. Saccharomyces cerevisiae Mus81-Mms4 is a catalytic, DNA structure-selective endonuclease. Nucleic Acids Res 36: 2182-2195.

Eid W, Steger M, El-Shemerly M, Ferretti LP, Pena-Diaz J, Konig C, Valtorta E, Sartori AA, Ferrari S. 2010. DNA end resection by CtIP and exonuclease 1 prevents genomic instability. EMBO Rep 11: 962-968.

Eissler CL, Mazon G, Powers BL, Savinov SN, Symington LS, Hall MC. 2014. The Cdk/cDc14 module controls activation of the Yen1 Holliday junction resolvase to promote genome stability. Mol Cell 54: 80-93.

Escribano-Diaz C, Orthwein A, Fradet-Turcotte A, Xing M, Young JT, Tkac J, Cook MA, Rosebrock AP, Munro M, Canny MD, et al. 2013. A cell cycle-dependent regulatory circuit composed of 53BP1-RIF1 and BRCA1-CtIP controls DNA repair pathway choice. Mol Cell 49: 872-883.

Fasching CL, Cejka P, Kowalczykowski SC, Heyer WD. 2015. Top3-Rmil dissolve Rad51-mediated D loops by a topoisomerase-based mechanism. Mol Cell 57: 595-606.

Fekairi S, Scaglione S, Chahwan C, Taylor ER, Tissier A, Coulon S, Dong MQ, Ruse C, Yates JR 3rd, Russell P, et al. 2009. Human SLX4 is a Holliday junction resolvase subunit that binds multiple DNA repair/recombination endonucleases. Cell 138: 78-89.

Feng Z, Scott SP, Bussen W, Sharma GG, Guo G, Pandita TK, Powell SN. 2011. Rad52 inactivation is synthetically lethal with BRCA2 deficiency. Proc Natl Acad Sci 108: 686-691.

Flaus A, Martin DM, Barton GJ, Owen-Hughes T. 2006. Identification of multiple distinct Snf2 subfamilies with conserved structural motifs. Nucleic Acids Res 34: 2887 2905. 
Forget AL, Kowalczykowski SC. 2012. Single-molecule imaging of DNA pairing by RecA reveals a three-dimensional homology search. Nature 482: 423-427.

Fortin GS, Symington LS. 2002. Mutations in yeast Rad51 that partially bypass the requirement for Rad55 and Rad57 in DNA repair by increasing the stability of Rad51-DNA complexes. EMBO J 21: 3160-3170.

Fricke WM, Brill SJ. 2003. Slx1-Slx4 is a second structurespecific endonuclease functionally redundant with Sgs1 Top3. Genes Dev 17: 1768-1778.

Fugger K, Mistrik M, Danielsen JR, Dinant C, Falck J, Bartek J, Lukas J, Mailand N. 2009. Human Fbh1 helicase contributes to genome maintenance via pro- and anti-recombinase activities. J Cell Biol 186: 655-663.

Fulconis R, Miné J, Bancaud A, Dutreix M, Viovy JL. 2006. Mechanism of RecA-mediated homologous recombination revisited by single molecule nanomanipulation. EMBO J 25: 4293-4304.

Galkin VE, Britt RL, Bane LB, Yu X, Cox MM, Egelman EH. 2011. Two modes of binding of DinI to RecA filament provide a new insight into the regulation of SOS response by DinI protein. J Mol Biol 408: 815-824.

Galletto R, Amitani I, Baskin RJ, Kowalczykowski SC. 2006. Direct observation of individual RecA filaments assembling on single DNA molecules. Nature 443: 875-878.

Gangloff S, McDonald JP, Bendixen C, Arthur L, Rothstein R. 1994. The yeast type I topoisomerase Top3 interacts with Sgs1, a DNA helicase homolog: A potential eukaryotic reverse gyrase. Mol Cell Biol 14: 8391-8398.

Garcia V, Phelps SE, Gray S, Neale MJ. 2011. Bidirectional resection of DNA double-strand breaks by Mre11 and Exo1. Nature 479: 241-244.

Gari K, Decaillet C, Stasiak AZ, Stasiak A, Constantinou A. 2008. The Fanconi anemia protein FANCM can promote branch migration of Holliday junctions and replication forks. Mol Cell 29: 141-148.

Gonda DK, Radding CM. 1983. By searching processively RecA protein pairs DNA molecules that share a limited stretch of homology. Cell 34: 647-654.

Haber JE. 1995. In vivo biochemistry: Physical monitoring of recombination induced by site-specific endonucleases. Bioessays 17: 609-620.

Han ES, Cooper DL, Persky NS, Sutera VA Jr, Whitaker RD, Montello ML, Lovett ST. 2006. RecJ exonuclease: Substrates, products and interaction with SSB. Nucleic Acids Res 34: 1084-1091.

Hanada K, Ukita T, Kohno Y, Saito K, Kato J, Ikeda H. 1997. RecQ DNA helicase is a suppressor of illegitimate recombination in Escherichia coli. Proc Natl Acad Sci 94: 38603865.

Handa N, Bianco PR, Baskin RJ, Kowalczykowski SC. 2005. Direct visualization of RecBCD movement reveals cotranslocation of the RecD motor after $\chi$ recognition. Mol Cell 17: 745-750.

Handa N, Amitani I, Gumlaw N, Sandler SJ, Kowalczykowski SC. 2009a. Single molecule analysis of a red fluorescent RecA protein reveals a defect in nucleoprotein filament nucleation that relates to its reduced biological functions. J Biol Chem 284: 18664-18673.

Handa N, Morimatsu K, Lovett ST, Kowalczykowski SC. 2009b. Reconstitution of initial steps of dsDNA break repair by the RecF pathway of E. coli. Genes Dev 23: $1234-1245$.

Handa N, Yang L, Dillingham MS, Kobayashi I, Wigley DB, Kowalczykowski SC. 2012. Molecular determinants responsible for recognition of the single-stranded DNA regulatory sequence, $\chi$, by RecBCD enzyme. Proc Natl Acad Sci 109: 8901-8906.

Harmon FG, Kowalczykowski SC. 1998. RecQ helicase, in concert with RecA and SSB proteins, initiates and disrupts DNA recombination. Genes Dev 12: 1134-1144.

Harmon FG, Kowalczykowski SC. 2001. Biochemical characterization of the DNA helicase activity of the Escherichia coli RecQ helicase. J Biol Chem 276: 232-243.

Harmon FG, DiGate RJ, Kowalczykowski SC. 1999. RecQ helicase and topoisomerase III comprise a novel DNA strand passage function: a conserved mechanism for control of DNA recombination. Mol Cell 3: 611-620.

Harmon FG, Brockman JP, Kowalczykowski SC. 2003. RecQ helicase stimulates both DNA catenation and changes in DNA topology by topoisomerase III. J Biol Chem 278: $42668-42678$.

Harris LD, Griffith JD. 1989. UvsY protein of bacteriophage $\mathrm{T} 4$ is an accessory protein for in vitro catalysis of strand exchange. J Mol Biol 206: 19-27.

Hegner M, Smith SB, Bustamante C. 1999. Polymerization and mechanical properties of single RecA-DNA filaments. Proc Natl Acad Sci 96: 10109-10114.

* Herbert M, Kalleas D, Cooney D, Lamb M, Lister L. 2015. Meiosis and maternal aging: Insights from aneuploid oocytes and trisomy births. Cold Spring Harb Perspect Biol 7: a017970.

* Heyer WD. 2015. Regulation of recombination and genomic maintenance. Cold Spring Harb Perspect Biol 7: a016501.

Heyer WD, Ehmsen KT, Liu J. 2010. Regulation of homologous recombination in eukaryotes. Annu Rev Genet 44: $113-139$.

Hilario J, Amitani I, Baskin RJ, Kowalczykowski SC. 2009. Direct imaging of human Rad51 nucleoprotein dynamics on individual DNA molecules. Proc Natl Acad Sci 106: 361-368.

Hiramoto T, Nakanishi T, Sumiyoshi T, Fukuda T, Matsuura S, Tauchi H, Komatsu K, Shibasaki Y, Inui H, Watatani M, et al. 1999. Mutations of a novel human RAD54 homologue, $R A D 54 B$, in primary cancer. Oncogene 18: $3422-$ 3426.

Ho CK, Mazon G, Lam AF, Symington LS. 2010. Mus81 and Yen1 promote reciprocal exchange during mitotic recombination to maintain genome integrity in budding yeast. Mol Cell 40: 988-1000.

Hoeijmakers JH. 2001. Genome maintenance mechanisms for preventing cancer. Nature 411: 366-374.

Holliday R. 1964. A mechanism for gene conversion in fungi. Genet Res 5: 282-304.

Hsieh P, Camerini-Otero CS, Camerini-Otero RD. 1992. The synapsis event in the homologous pairing of DNAs: RecA recognizes and pairs less than one helical repeat of DNA. Proc Natl Acad Sci 89: 6492-6496.

Hu Y, Raynard S, Sehorn MG, Lu X, Bussen W, Zheng L, Stark JM, Barnes EL, Chi P, Janscak P, et al. 2007. RECQL5/Recql5 helicase regulates homologous recombination and suppresses tumor formation via disruption 
of Rad51 presynaptic filaments. Genes Dev 21: 30733084.

Huertas P, Jackson SP. 2009. Human CtIP mediates cell cycle control of DNA end resection and double strand break repair. J Biol Chem 284: 9558-9565.

* Hunter N. 2015. Meiotic recombination: The essence of heredity. Cold Spring Harb Perspect Biol doi: 10.1101/ cshperspect.a016618.

Interthal H, Heyer WD. 2000. MUS81 encodes a novel helix-hairpin-helix protein involved in the response to UV- and methylation-induced DNA damage in Saccharomyces cerevisiae. Mol Gen Genet 263: 812-827.

Ip SC, Rass U, Blanco MG, Flynn HR, Skehel JM, West SC. 2008. Identification of Holliday junction resolvases from humans and yeast. Nature 456: 357-361.

Ira G, Malkova A, Liberi G, Foiani M, Haber JE. 2003. Srs2 and Sgs1-Top3 suppress crossovers during doublestrand break repair in yeast. Cell 115: 401-411.

Iwasaki H, Takahagi M, Nakata A, Shinagawa H. 1992. Escherichia coli RuvA and RuvB proteins specifically interact with Holliday junctions and promote branch migration. Genes Dev 6: 2214-2220.

Jensen RB, Carreira A, Kowalczykowski SC. 2010. Purified human BRCA2 stimulates RAD51-mediated recombination. Nature 467: 678-683.

Johnson RD, Symington LS. 1995. Functional differences and interactions among the putative RecA homologs Rad51, Rad55, and Rad57. Mol Cell Biol 15: 4843-4850.

Joo C, McKinney SA, Nakamura M, Rasnik I, Myong S, Ha T. 2006. Real-time observation of RecA filament dynamics with single monomer resolution. Cell 126: 515-527.

Julin DA, Riddles PW, Lehman IR. 1986. On the mechanism of pairing of single- and double-stranded DNA molecules by the recA and single-stranded DNA-binding proteins of Escherichia coli. J Biol Chem 261: 1025-1030.

Kaidi A, Weinert BT, Choudhary C, Jackson SP. 2010. Human SIRT6 promotes DNA end resection through CtIP deacetylation. Science 329: 1348-1353.

Kantake N, Madiraju MV, Sugiyama T, Kowalczykowski SC. 2002. Escherichia coli RecO protein anneals ssDNA complexed with its cognate ssDNA-binding protein: A common step in genetic recombination. Proc Natl Acad Sci 99: 15327-15332.

Karow JK, Constantinou A, Li JL, West SC, Hickson ID. 2000. The Bloom's syndrome gene product promotes branch migration of Holliday junctions. Proc Natl Acad Sci 97: 6504-6508.

Keyamura K, Sakaguchi C, Kubota Y, Niki H, Hishida T. 2013. RecA protein recruits structural maintenance of chromosomes (SMC)-like RecN protein to DNA double-strand breaks. J Biol Chem 288: 29229-29237.

Kim J, Kim JH, Lee SH, Kim DH, Kang HY, Bae SH, Pan ZQ, Seo YS. 2002. The novel human DNA helicase hFBH1 is an F-box protein. J Biol Chem 277: 24530-24537.

Kodadek T, Gan DC, Stemke-Hale K. 1989. The phage T4 uvs $\mathrm{Y}$ recombination protein stabilizes presynaptic filaments. J Biol Chem 264: 16451-16457.

Kogoma T. 1997. Stable DNA replication: Interplay between DNA replication, homologous recombination, and transcription. Microbiol Mol Biol Rev 61: 212-238.
Kottemann MC, Smogorzewska A. 2013. Fanconi anaemia and the repair of Watson and Crick DNA crosslinks. $\mathrm{Na}$ ture 493: 356-363.

Kowalczykowski SC. 1991. Biochemical and biological function of Escherichia coli RecA protein: Behavior of mutant RecA proteins. Biochimie 73: 289-304.

Kowalczykowski SC. 2000. Initiation of genetic recombination and recombination-dependent replication. Trends Biochem Sci 25: 156-165.

Kowalczykowski SC. 2008. Structural biology: Snapshots of DNA repair. Nature 453: 463-466.

Kowalczykowski SC, Eggleston AK. 1994. Homologous pairing and DNA strand-exchange proteins. Annu Rev Biochem 63: 991-1043.

Kowalczykowski SC, Krupp RA. 1987. Effects of Escherichia coli SSB protein on the single-stranded DNA-dependent ATPase activity of Escherichia coli RecA protein. Evidence that SSB protein facilitates the binding of RecA protein to regions of secondary structure within single-stranded DNA. J Mol Biol 193: 97-113.

Kowalczykowski SC, Krupp RA. 1989. Biochemical events essential to the recombination activity of Escherichia coli RecA protein. II: Co-dominant effects of RecA142 protein on wild-type RecA protein function. J Mol Biol 207: 735-747.

Kowalczykowski SC, Clow J, Somani R, Varghese A. 1987. Effects of the Escherichia coli SSB protein on the binding of Escherichia coli RecA protein to single-stranded DNA. Demonstration of competitive binding and the lack of a specific protein-protein interaction. J Mol Biol 193: 8195.

Kowalczykowski SC, Dixon DA, Eggleston AK, Lauder SD, Rehrauer WM. 1994. Biochemistry of homologous recombination in Escherichia coli. Microbiol Rev 58: 401465.

Krajewski WW, Fu X, Wilkinson M, Cronin NB, Dillingham MS, Wigley DB. 2014. Structural basis for translocation by AddAB helicase-nuclease and its arrest at $\chi$ sites. $\mathrm{Na}$ ture 508: 416-419.

Krejci L, Van Komen S, Li Y, Villemain J, Reddy MS, Klein H, Ellenberger T, Sung P. 2003. DNA helicase Srs2 disrupts the Rad51 presynaptic filament. Nature 423: 305-309.

Kreuzer KN. 2000. Recombination-dependent DNA replication in phage T4. Trends Biochem Sci 25: 165-173.

Kuzminov A. 1999. Recombinational repair of DNA damage in Escherichia coli and bacteriophage $\lambda$. Microbiol Mol Biol Rev 63: 751-813.

* Lam I, Keeney S. 2015. Mechanism and regulation of meiotic recombination initiation. Cold Spring Harb Perspect Biol 7: a016634.

Lange SS, Takata K, Wood RD. 2011. DNA polymerases and cancer. Nat Rev Cancer 11: 96-110.

Lao JP, Oh SD, Shinohara M, Shinohara A, Hunter N. 2008. Rad52 promotes postinvasion steps of meiotic doublestrand-break repair. Mol Cell 29: 517-524.

Lavery PE, Kowalczykowski SC. 1992. A postsynaptic role for single-stranded DNA-binding protein in recA proteinpromoted DNA strand exchange. J Biol Chem 267: 9315-9320.

Léger JF, Robert J, Bourdieu L, Chatenay D, Marko JF. 1998. RecA binding to a single double-stranded DNA molecule: 
S.C. Kowalczykowski

A possible role of DNA conformational fluctuations. Proc Natl Acad Sci 95: 12295-12299.

Levy A, Goren MG, Yosef I, Auster O, Manor M, Amitai G, Edgar R, Qimron U, Sorek R. 2015. CRISPR adaptation biases explain preference for acquisition of foreign DNA. Nature 520: 505-510.

Li X, Heyer WD. 2009. RAD54 controls access to the invading $3^{\prime}$-OH end after RAD51-mediated DNA strand invasion in homologous recombination in Saccharomyces cerevisiae. Nucleic Acids Res 37: 638-646.

* Lisby M, Rothstein R. 2015. Cell biology of mitotic recombination. Cold Spring Harb Perspect Biol 7: a016535.

Lisby M, Barlow JH, Burgess RC, Rothstein R. 2004. Choreography of the DNA damage response: Spatiotemporal relationships among checkpoint and repair proteins. Cell 118: $699-713$.

Liu N, Lamerdin JE, Tebbs RS, Schild D, Tucker JD, Shen MR, Brookman KW, Siciliano MJ, Walter CA, Fan W, et al. 1998. XRCC2 and XRCC3, new human Rad51-family members, promote chromosome stability and protect against DNA cross-links and other damages. Mol Cell 1: 783-793.

Liu J, Doty T, Gibson B, Heyer WD. 2010. Human BRCA2 protein promotes RAD51 filament formation on RPAcovered single-stranded DNA. Nat Struct Mol Biol 17: $1260-1262$.

Liu J, Renault L, Veaute X, Fabre F, Stahlberg H, Heyer WD. 2011a. Rad51 paralogues Rad55-Rad57 balance the antirecombinase Srs2 in Rad51 filament formation. Nature 479: $245-248$.

Liu T, Wan L, Wu Y, Chen J, Huang J. 2011b. hSWS1. SWSAP1 is an evolutionarily conserved complex required for efficient homologous recombination repair. J Biol Chem 286: 41758-41766.

Liu B, Baskin RJ, Kowalczykowski SC. 2013. DNA unwinding heterogeneity by RecBCD results from static molecules able to equilibrate. Nature 500: 482-485.

Lohman TM, Ferrari ME. 1994. Escherichia coli singlestranded DNA-binding protein: Multiple DNA-binding modes and cooperativities. Annu Rev Biochem 63: 527570.

Loveday C, Turnbull C, Ramsay E, Hughes D, Ruark E, Frankum JR, Bowden G, Kalmyrzaev B, Warren-Perry M, Snape K, et al. 2011. Germline mutations in RAD51D confer susceptibility to ovarian cancer. Nat Genet 43: 879 882.

Lovett ST, Kolodner RD. 1989. Identification and purification of a single-stranded-DNA-specific exonuclease encoded by the recJ gene of Escherichia coli. Proc Natl Acad Sci 86: 2627-2631.

Lovett ST, Mortimer RK. 1987. Characterization of null mutants of the RAD55 gene of Saccharomyces cerevisiae: Effects of temperature, osmotic strength and mating type. Genetics 116: 547-553.

Lusetti SL, Drees JC, Stohl EA, Seifert HS, Cox MM. 2004a. The DinI and RecX proteins are competing modulators of RecA function. J Biol Chem 279: 55073-55079.

Lusetti SL, Voloshin ON, Inman RB, Camerini-Otero RD, Cox MM. 2004b. The DinI protein stabilizes RecA protein filaments. J Biol Chem 279: 30037-30046.
Madiraju MVVS, Templin A, Clark AJ. 1988. Properties of a mutant recA-encoded protein reveal a possible role for Escherichia coli recF-encoded protein in genetic recombination. Proc Natl Acad Sci 85: 6592-6596.

Martin V, Chahwan C, Gao H, Blais V, Wohlschlegel J, Yates JR 3rd, McGowan CH, Russell P. 2006. Sws1 is a conserved regulator of homologous recombination in eukaryotic cells. EMBO J 25: 2564-2574.

Masson JY, Stasiak AZ, Stasiak A, Benson FE, West SC. 2001a. Complex formation by the human RAD51C and XRCC3 recombination repair proteins. Proc Natl Acad Sci 98: $8440-8446$.

Masson JY, Tarsounas MC, Stasiak AZ, Stasiak A, Shah R, McIlwraith MJ, Benson FE, West SC. 2001b. Identification and purification of two distinct complexes containing the five RAD51 paralogs. Genes Dev 15: 3296-3307.

Matulova P, Marini V, Burgess RC, Sisakova A, Kwon Y, Rothstein R, Sung P, Krejci L. 2009. Cooperativity of Mus81.Mms4 with Rad54 in the resolution of recombination and replication intermediates. J Biol Chem 284: 7733-7745.

Mazin AV, Bornarth CJ, Solinger JA, Heyer WD, Kowalczykowski SC. 2000. Rad54 protein is targeted to pairing loci by the Rad51 nucleoprotein filament. Mol Cell 6: $583-$ 592.

Mazin AV, Alexeev AA, Kowalczykowski SC. 2003. A novel function of Rad54 protein. Stabilization of the Rad51 nucleoprotein filament. J Biol Chem 278: 14029-14036.

Mazina OM, Mazin AV. 2004. Human Rad54 protein stimulates DNA strand exchange activity of hRad51 protein in the presence of $\mathrm{Ca}^{2+}$. J Biol Chem 279: 52042-52051.

Mazina OM, Mazin AV. 2008. Human Rad54 protein stimulates human Mus81-Emel endonuclease. Proc Natl Acad Sci 105: 18249-18254.

Mazina OM, Rossi MJ, Deakyne JS, Huang F, Mazin AV. 2012. Polarity and bypass of DNA heterology during branch migration of Holliday junctions by human RAD54, BLM, and RECQ1 proteins. J Biol Chem 287: $11820-11832$.

Mazon G, Symington LS. 2013. Mph1 and Mus81-Mms4 prevent aberrant processing of mitotic recombination intermediates. Mol Cell 52: 63-74.

McGlynn P, Al-Deib AA, Liu J, Marians KJ, Lloyd RG. 1997. The DNA replication protein PriA and the recombination protein RecG bind D-loops. J Mol Biol 270: 212 221.

McIlwraith MJ, West SC. 2008. DNA repair synthesis facilitates RAD52-mediated second-end capture during DSB repair. Mol Cell 29: 510-516.

* Mehta A, Haber JE. 2014. Sources of DNA double-strand breaks and models of recombinational DNA repair. Cold Spring Harb Perspect Biol 6: a016428.

Meindl A, Hellebrand H, Wiek C, Erven V, Wappenschmidt B, Niederacher D, Freund M, Lichtner P, Hartmann L, Schaal H, et al. 2010. Germline mutations in breast and ovarian cancer pedigrees establish $R A D 51 C$ as a human cancer susceptibility gene. Nat Genet 42: 410-414.

Mendonca VM, Klepin HD, Matson SW. 1995. DNA helicases in recombination and repair: Construction of a $\Delta u v r D \Delta h e l D \Delta r e c Q$ mutant deficient in recombination and repair. J Bacteriol 177: 1326-1335. 
Menetski JP, Kowalczykowski SC. 1985. Interaction of recA protein with single-stranded DNA. Quantitative aspects of binding affinity modulation by nucleotide cofactors. J Mol Biol 181: 281-295.

Menetski JP, Bear DG, Kowalczykowski SC. 1990. Stable DNA heteroduplex formation catalyzed by the Escherichia coli RecA protein in the absence of ATP hydrolysis. Proc Natl Acad Sci 87: 21-25.

Mimitou EP, Symington LS. 2008. Sae2, Exol and Sgs1 collaborate in DNA double-strand break processing. Nature 455: $770-774$.

Miné J, Disseau L, Takahashi M, Cappello G, Dutreix M, Viovy JL. 2007. Real-time measurements of the nucleation, growth and dissociation of single Rad51-DNA nucleoprotein filaments. Nucleic Acids Res 35: 71717187.

Miné-Hattab J, Rothstein R. 2012. Increased chromosome mobility facilitates homology search during recombination. Nat Cell Biol 14: 510-517.

Mitchel K, Lehner K, Jinks-Robertson S. 2013. Heteroduplex DNA position defines the roles of the Sgs1, Srs2, and Mphl helicases in promoting distinct recombination outcomes. PLoS Genet 9: e1003340.

Modesti M, Ristic D, van der Heijden T, Dekker C, van Mameren J, Peterman EJ, Wuite GJ, Kanaar R, Wyman C. 2007. Fluorescent human RAD51 reveals multiple nucleation sites and filament segments tightly associated along a single DNA molecule. Structure 15: 599-609.

Moldovan GL, Dejsuphong D, Petalcorin MI, Hofmann K, Takeda S, Boulton SJ, D’Andrea AD. 2012. Inhibition of homologous recombination by the PCNA-interacting protein PARI. Mol Cell 45: 75-86.

Morel P, Hejna JA, Ehrlich SD, Cassuto E. 1993. Antipairing and strand transferase activities of E. coli helicase II (UvrD). Nucleic Acids Res 21: 3205-3209.

Morimatsu K, Kowalczykowski SC. 2003. RecFOR proteins load RecA protein onto gapped DNA to accelerate DNA strand exchange: A universal step of recombinational repair. Mol Cell 11: 1337-1347.

Morimatsu K, Kowalczykowski SC. 2014. RecQ helicase and RecJ nuclease provide complementary functions to resect DNA for homologous recombination. Proc Natl Acad Sci 111: E5133-E5142.

Morimatsu K, Wu Y, Kowalczykowski SC. 2012. RecFOR proteins target RecA protein to a DNA gap with either DNA or RNA at the $5^{\prime}$ terminus: Implication for repair of stalled replication forks. J Biol Chem 287: 35621-35630.

* Morrical SW. 2015. DNA-pairing and annealing processes in homologous recombination and homology-directed repair. Cold Spring Harb Perspect Biol 7: a016444.

Mosig G. 1987. The essential role of recombination in phage T4 growth. Annu Rev Genet 21: 347-371.

Mullen JR, Nallaseth FS, Lan YQ, Slagle CE, Brill SJ. 2005 Yeast Rmil/Nce4 controls genome stability as a subunit of the Sgs1-Top3 complex. Mol Cell Biol 25: 4476-4487.

Nakayama H, Nakayama K, Nakayama R, Irino N, Nakayama Y, Hanawalt PC. 1984. Isolation and genetic characterization of a thymineless death-resistant mutant of Escherichia coli K12: Identification of a new mutation (recQ1) that blocks the recF recombination pathway. Mol Gen Genet 195: 474-480.
Nasmyth KA. 1982. Molecular genetics of yeast mating type. Annu Rev Genet 16: 439-500.

New JH, Kowalczykowski SC. 2002. Rad52 protein has a second stimulatory role in DNA strand exchange that complements replication protein-A function. J Biol Chem 277: 26171-26176.

New JH, Sugiyama T, Zaitseva E, Kowalczykowski SC. 1998. Rad52 protein stimulates DNA strand exchange by Rad51 and replication protein A. Nature 391: 407-410.

Nimonkar AV, Amitani I, Baskin RJ, Kowalczykowski SC. 2007. Single molecule imaging of Tid1/Rdh54, a Rad54 homolog that translocates on duplex DNA and can disrupt joint molecules. J Biol Chem 282: 30776-30784.

Nimonkar AV, Ozsoy AZ, Genschel J, Modrich P, Kowalczykowski SC. 2008. Human exonuclease 1 and BLM helicase interact to resect DNA and initiate DNA repair. Proc Natl Acad Sci 105: 16906-16911.

Nimonkar AV, Sica RA, Kowalczykowski SC. 2009. Rad52 promotes second-end DNA capture in double-stranded break repair to form complement-stabilized joint molecules. Proc Natl Acad Sci 106: 3077-3082.

Nimonkar AV, Genschel J, Kinoshita E, Polaczek P, Campbell JL, Wyman C, Modrich P, Kowalczykowski SC. 2011. BLM-DNA2-RPA-MRN and EXO1-BLM-RPAMRN constitute two DNA end resection machineries for human DNA break repair. Genes Dev 25: 350-362.

Nimonkar AV, Dombrowski CC, Siino JS, Stasiak AZ, Stasiak A, Kowalczykowski SC. 2012. Saccharomyces cerevisiae Dmc1 and Rad51 proteins preferentially function with Tid1 and Rad54 proteins, respectively, to promote DNA strand invasion during genetic recombination. J Biol Chem 287: 28727-28737.

Niu H, Chung WH, Zhu Z, Kwon Y, Zhao W, Chi P, Prakash R, Seong C, Liu D, Lu L, et al. 2010. Mechanism of the ATP-dependent DNA end-resection machinery from Saccharomyces cerevisiae. Nature 467: 108-111.

Ogrunc M, Sancar A. 2003. Identification and characterization of human MUS81-MMS4 structure-specific endonuclease. J Biol Chem 278: 21715-21720.

Opresko PL, Sowd G, Wang H. 2009. The Werner syndrome helicase/exonuclease processes mobile D-loops through branch migration and degradation. PLoS ONE 4: e4825.

Orr N, Lemnrau A, Cooke R, Fletcher O, Tomczyk K, Jones M, Johnson N, Lord CJ, Mitsopoulos C, Zvelebil M, et al. 2012. Genome-wide association study identifies a common variant in $R A D 51 B$ associated with male breast cancer risk. Nat Genet 44: 1182-1184.

Orren DK, Theodore S, Machwe A. 2002. The Werner syndrome helicase/exonuclease (WRN) disrupts and degrades D-loops in vitro. Biochemistry 41: 13483-13488.

Panier S, Boulton SJ. 2014. Double-strand break repair: 53BP1 comes into focus. Nat Rev Mol Cell Biol 15: 7-18.

Pâques F, Haber JE. 1999. Multiple pathways of recombination induced by double-strand breaks in Saccharomyces cerevisiae. Microbiol Mol Biol Rev 63: 349-404.

Paull TT, Gellert M. 1998. The $3^{\prime}$ to $5^{\prime}$ exonuclease activity of Mre 11 facilitates repair of DNA double-strand breaks. Mol Cell 1: 969-979.

Paull TT, Gellert M. 1999. Nbs1 potentiates ATP-driven DNA unwinding and endonuclease cleavage by the Mre11/Rad50 complex. Genes Dev 13: 1276-1288. 
S.C. Kowalczykowski

Peacock-Villada A, Yang D, Danilowicz C, Feinstein E, Pollock N, McShan S, Coljee V, Prentiss M. 2012. Complementary strand relocation may play vital roles in RecAbased homology recognition. Nucleic Acids Res 40: 10441-10451.

Pellegrino S, Radzimanowski J, de Sanctis D, Boeri Erba E, McSweeney S, Timmins J. 2012. Structural and functional characterization of an SMC-like protein $\mathrm{RecN}$ : New insights into double-strand break repair. Structure 20: 2076-2089.

Pepe A, West SC. 2014. Substrate specificity of the MUS81EME2 structure selective endonuclease. Nucleic Acids Res 42: 3833-3845.

Petrova V, Chen SH, Molzberger ET, Tomko E, ChitteniPattu S, Jia H, Ordabayev Y, Lohman TM, Cox MM 2015. Active displacement of RecA filaments by UvrD translocase activity. Nucleic Acids Res 43: 4133-4149.

Petukhova G, Stratton S, Sung P. 1998. Catalysis of homologous DNA pairing by yeast Rad51 and Rad54 proteins. Nature 393: 91-94.

Petukhova G, Stratton SA, Sung P. 1999. Single strand DNA binding and annealing activities in the yeast recombination factor Rad59. J Biol Chem 274: 33839-33842.

Petukhova G, Sung P, Klein H. 2000. Promotion of Rad51dependent D-loop formation by yeast recombination factor Rdh54/Tid1. Genes Dev 14: 2206-2215.

Picksley SM, Attfield PV, Lloyd RG. 1984. Repair of DNA double-strand breaks in Escherichia coli K12 requires a functional recN product. Mol Gen Genet 195: 267-274.

Ponticelli AS, Schultz DW, Taylor AF, Smith GR. 1985. XDependent DNA strand cleavage by RecBC enzyme. Cell 41: $145-151$.

Popuri V, Bachrati CZ, Muzzolini L, Mosedale G, Costantini S, Giacomini E, Hickson ID, Vindigni A. 2008. The human RecQ helicases, BLM and RECQ1, display distinct DNA substrate specificities. J Biol Chem 283: 1776617776.

Prakash R, Krejci L, Van Komen S, Anke Schurer K, Kramer W, Sung P. 2005. Saccharomyces cerevisiae MPH1 gene, required for homologous recombination-mediated mutation avoidance, encodes a $3^{\prime}$ to $5^{\prime}$ DNA helicase. J Biol Chem 280: 7854-7860.

Prakash R, Satory D, Dray E, Papusha A, Scheller J, Kramer W, Krejci L, Klein H, Haber JE, Sung P, et al. 2009. Yeast Mph1 helicase dissociates Rad51-made D-loops: Implications for crossover control in mitotic recombination. Genes Dev 23: 67-79.

* Prakash R, Zhang Y, Feng W, Jasin M. 2015. Homologous recombination and human health: The roles of BRCA1, BRCA2, and associated proteins. Cold Spring Harb Perspect Biol 7: a016600.

Prasad TK, Robertson RB, Visnapuu ML, Chi P, Sung P, Greene EC. 2007. A DNA-translocating Snf2 molecular motor: Saccharomyces cerevisiae Rdh54 displays processive translocation and extrudes DNA loops. J Mol Biol 369: 940-953.

Prévost C, Takahashi M. 2003. Geometry of the DNA strands within the RecA nucleofilament: Role in homologous recombination. Q Rev Biophys 36: 429-453.

Rafferty JB, Sedelnikova SE, Hargreaves D, Artymiuk PJ, Baker PJ, Sharples GJ, Mahdi AA, Lloyd RG, Rice DW.
1996. Crystal structure of DNA recombination protein RuvA and a model for its binding to the Holliday junction. Science 274: 415-421.

Ragunathan K, Joo C, Ha T. 2011. Real-time observation of strand exchange reaction with high spatiotemporal resolution. Structure 19: 1064-1073.

Ragunathan K, Liu C, Ha T. 2012. RecA filament sliding on DNA facilitates homology search. eLife 1: e00067.

Rahman N, Seal S, Thompson D, Kelly P, Renwick A, Elliott A, Reid S, Spanova K, Barfoot R, Chagtai T, et al. 2007. $P A L B 2$, which encodes a BRCA2-interacting protein, is a breast cancer susceptibility gene. Nat Genet 39: 165-167.

Rass U, Compton SA, Matos J, Singleton MR, Ip SC, Blanco MG, Griffith JD, West SC. 2010. Mechanism of Holliday junction resolution by the human GEN1 protein. Genes Dev 24: 1559-1569.

Raynard S, Bussen W, Sung P. 2006. A double Holliday junction dissolvasome comprising BLM, topoisomerase III $\alpha$, and BLAP75. J Biol Chem 281: 13861-13864.

* Reams AB, Roth JR. 2015. Mechanisms of gene duplication and amplification. Cold Spring Harb Perspect Biol 7: a016592.

Reid S, Schindler D, Hanenberg H, Barker K, Hanks S, Kalb R, Neveling K, Kelly P, Seal S, Freund M, et al. 2007. Biallelic mutations in PALB2 cause Fanconi anemia subtype FA-N and predispose to childhood cancer. Nat Genet 39: $162-164$.

Reyes ED, Patidar PL, Uranga LA, Bortoletto AS, Lusetti SL. 2010. RecN is a cohesin-like protein that stimulates intermolecular DNA interactions in vitro. J Biol Chem 285: 16521-16529.

Ristic D, Wyman C, Paulusma C, Kanaar R. 2001. The architecture of the human Rad54-DNA complex provides evidence for protein translocation along DNA. Proc Natl Acad Sci 98: 8454-8460.

Robertson RB, Moses DN, Kwon Y, Chan P, Chi P, Klein H, Sung P, Greene EC. 2009a. Structural transitions within human Rad51 nucleoprotein filaments. Proc Natl Acad Sci 106: 12688-12693.

Robertson RB, Moses DN, Kwon Y, Chan P, Zhao W, Chi P, Klein H, Sung P, Greene EC. 2009b. Visualizing the disassembly of $S$. cerevisiae Rad51 nucleoprotein filaments. J Mol Biol 388: 703-720.

Rocha EP, Cornet E, Michel B. 2005. Comparative and evolutionary analysis of the bacterial homologous recombination systems. PLoS Genet 1: e15.

Roman LJ, Kowalczykowski SC. 1989a. Characterization of the adenosinetriphosphatase activity of the Escherichia coli RecBCD enzyme: Relationship of ATP hydrolysis to the unwinding of duplex DNA. Biochemistry 28: 28732881.

Roman LJ, Kowalczykowski SC. 1989b. Characterization of the helicase activity of the Escherichia coli RecBCD enzyme using a novel helicase assay. Biochemistry 28: 28632873.

Rossi MJ, Mazin AV. 2008. Rad51 protein stimulates the branch migration activity of Rad54 protein. J Biol Chem 283: 24698-24706.

Sanchez H, Kidane D, Castillo Cozar M, Graumann PL, Alonso JC. 2006. Recruitment of Bacillus subtilis RecN 
to DNA double-strand breaks in the absence of DNA end processing. J Bacteriol 188: 353-360.

Sanchez H, Cardenas PP, Yoshimura SH, Takeyasu K, Alonso JC. 2008. Dynamic structures of Bacillus subtilis RecNDNA complexes. Nucleic Acids Res 36: 110-120.

Sartori AA, Lukas C, Coates J, Mistrik M, Fu S, Bartek J, Baer R, Lukas J, Jackson SP. 2007. Human CtIP promotes DNA end resection. Nature 450: 509-514.

Sasanuma H, Tawaramoto MS, Lao JP, Hosaka H, Sanda E, Suzuki M, Yamashita E, Hunter N, Shinohara M, Nakagawa A, et al. 2013. A new protein complex promoting the assembly of Rad51 filaments. Nature Commun 4: 1676.

* Schiller CB, Seifert FU, Linke-Winnebeck C, Hopfner KP. 2014. Structural studies of DNA end detection and resection in homologous recombination. Cold Spring Harb Perspect Biol 6: a017962.

Schmutte C, Marinescu RC, Sadoff MM, Guerrette S, Overhauser J, Fishel R. 1998. Human exonuclease I interacts with the mismatch repair protein hMSH2. Cancer Res 58: 4537-4542.

Schwartz EK, Wright WD, Ehmsen KT, Evans JE, Stahlberg H, Heyer WD. 2012. Mus81-Mms4 functions as a single heterodimer to cleave nicked intermediates in recombinational DNA repair. Mol Cell Biol 32: 3065-3080.

Schwendener S, Raynard S, Paliwal S, Cheng A, Kanagaraj R, Shevelev I, Stark JM, Sung P, Janscak P. 2010. Physical interaction of RECQ5 helicase with RAD51 facilitates its anti-recombinase activity. J Biol Chem 285: 1573915745.

Seitz EM, Haseltine CA, Kowalczykowski SC. 2001. DNA recombination and repair in the archaea. Adv Appl Microbiol 50: 101-169.

Shah PP, Zheng X, Epshtein A, Carey JN, Bishop DK, Klein HL. 2010. Swi2/Snf2-related translocases prevent accumulation of toxic Rad51 complexes during mitotic growth. Mol Cell 39: 862-872.

Sharples GJ, Leach DR. 1995. Structural and functional similarities between the SbcCD proteins of Escherichia coli and the RAD50 and MRE11 (RAD32) recombination and repair proteins of yeast. Mol Microbiol 17: 12151217.

Shereda RD, Kozlov AG, Lohman TM, Cox MM, Keck JL. 2008. SSB as an organizer/mobilizer of genome maintenance complexes. Crit Rev Biochem Mol Biol 43: 289318.

Shibata T, DasGupta C, Cunningham RP, Radding CM. 1979. Purified Escherichia coli recA protein catalyzes homologous pairing of superhelical DNA and singlestranded fragments. Proc Natl Acad Sci 76: 1638-1642.

Shim KS, Schmutte C, Tombline G, Heinen CD, Fishel R. 2004. hXRCC2 enhances ADP/ATP processing and strand exchange by hRAD51. J Biol Chem 279: 3038530394.

Shinohara A, Ogawa T. 1998. Stimulation by Rad52 of yeast Rad51-mediated recombination. Nature 391: 404-407.

Shinohara A, Shinohara M, Ohta T, Matsuda S, Ogawa T. 1998. Rad52 forms ring structures and co-operates with RPA in single-strand DNA annealing. Genes Cells 3: 145156.

Shivashankar GV, Feingold M, Krichevsky O, Libchaber A. 1999. RecA polymerization on double-stranded DNA by using single-molecule manipulation: the role of ATP hydrolysis. Proc Natl Acad Sci 96: 7916-7921.

Shor E, Weinstein J, Rothstein R. 2005. A genetic screen for top3 suppressors in Saccharomyces cerevisiae identifies SHU1, SHU2, PSY3 and CSM2: Four genes involved in error-free DNA repair. Genetics 169: 12751289.

Sigurdsson S, Van Komen S, Bussen W, Schild D, Albala JS, Sung P. 2001. Mediator function of the human Rad51BRad51C complex in Rad51/RPA-catalyzed DNA strand exchange. Genes Dev 15: 3308-3318.

Simandlova J, Zagelbaum J, Payne MJ, Chu WK, Shevelev I, Hanada K, Chatterjee S, Reid DA, Liu Y, Janscak P, et al. 2013. FBH1 helicase disrupts RAD51 filaments in vitro and modulates homologous recombination in mammalian cells. J Biol Chem 288: 34168-34180.

Singh TR, Ali AM, Busygina V, Raynard S, Fan Q, Du CH, Andreassen PR, Sung P, Meetei AR. 2008. BLAP18/ RMI2, a novel OB-fold-containing protein, is an essential component of the Bloom helicase-double Holliday junction dissolvasome. Genes Dev 22: 2856-2868.

Singleton MR, Dillingham MS, Gaudier M, Kowalczykowski SC, Wigley DB. 2004. Crystal structure of RecBCD enzyme reveals a machine for processing DNA breaks. Nature 432: 187-193.

Smith GR. 1991. Conjugational recombination in Escherichia coli: Myths and mechanisms. Cell 64: 19-27.

Solinger JA, Heyer WD. 2001. Rad54 protein stimulates the postsynaptic phase of Rad51 protein-mediated DNA strand exchange. Proc Natl Acad Sci 98: 8447-8453.

Solinger JA, Kiianitsa K, Heyer WD. 2002. Rad54, a Swi2/ Snf2-like recombinational repair protein, disassembles Rad51:dsDNA filaments. Mol Cell 10: 1175-1188.

Sommers JA, Rawtani N, Gupta R, Bugreev DV, Mazin AV, Cantor SB, Brosh RM Jr, 2009. FANCJ uses its motor ATPase to destabilize protein-DNA complexes, unwind triplexes, and inhibit RAD51 strand exchange. J Biol Chem 284: 7505-7517.

Somyajit K, Subramanya S, Nagaraju G. 2010. RAD51C: A novel cancer susceptibility gene is linked to Fanconi anemia and breast cancer. Carcinogenesis 31: 2031-2038.

Spies M, Kowalczykowski SC. 2005. Homologous recombination by RecBCD and RecF pathways. In The bacterial chromosome (ed. Higgins NP), pp. 389-403. ASM Press, Washington, DC.

Spies M, Kowalczykowski SC. 2006. The RecA binding locus of RecBCD is a general domain for recruitment of DNA strand exchange proteins. Mol Cell 21: 573-580.

* Spies M, Fishel R. 2015. Mismatch repair during homologous and homeologous recombination. Cold Spring Harb Perspect Biol 7: a022657.

Spies M, Bianco PR, Dillingham MS, Handa N, Baskin RJ, Kowalczykowski SC. 2003. A molecular throttle: The recombination hotspot $\chi$ controls DNA translocation by the RecBCD helicase. Cell 114: 647-654.

Spies M, Dillingham MS, Kowalczykowski SC. 2005. Translocation by the RecB motor is an absolute requirement for $\chi$ - recognition and RecA protein loading by RecBCD enzyme. J Biol Chem 280: 37078-37087. 
S.C. Kowalczykowski

Spies M, Amitani I, Baskin RJ, Kowalczykowski SC. 2007. RecBCD enzyme switches lead motor subunits in response to $\chi$ recognition. Cell 131: 694-705.

Stasiak A, Egelman EH. 1994. Structure and function of RecA-DNA complexes. Experientia 50: 192-203.

Stohl EA, Brockman JP, Burkle KL, Morimatsu K, Kowalczykowski SC, Seifert HS. 2003. Escherichia coli RecX inhibits RecA recombinase and coprotease activities in vitro and in vivo. J Biol Chem 278: 2278-2285.

Sturzenegger A, Burdova K, Kanagaraj R, Levikova M, Pinto C, Cejka P, Janscak P. 2014. DNA2 cooperates with the WRN and BLM RecQ helicases to mediate long-range DNA end resection in human cells. J Biol Chem 289: 27314-27326.

Su GC, Chung CI, Liao CY, Lin SW, Tsai CT, Huang T, Li HW, Chi P. 2014. Enhancement of ADP release from the RAD51 presynaptic filament by the SWI5-SFR1 complex. Nucleic Acids Res 42: 349-358.

* Subramanian VV, Hochwagen A. 2014. The meiotic checkpoint network: Step-by-step through meiotic prophase. Cold Spring Harb Perspect Biol 6: a016675.

Sugawara N, Ira G, Haber JE. 2000. DNA length dependence of the single-strand annealing pathway and the role of Saccharomyces cerevisiae RAD59 in double-strand break repair. Mol Cell Biol 20: 5300-5309.

Sugiyama T, Zaitseva EM, Kowalczykowski SC. 1997. A single-stranded DNA-binding protein is needed for efficient presynaptic complex formation by the Saccharomyces cerevisiae Rad51 protein. J Biol Chem 272: 7940-7945.

Sugiyama T, New JH, Kowalczykowski SC. 1998. DNA annealing by RAD52 protein is stimulated by specific interaction with the complex of replication protein A and single-stranded DNA. Proc Natl Acad Sci 95: 60496054.

Sugiyama T, Kantake N, Wu Y, Kowalczykowski SC. 2006. Rad52-mediated DNA annealing after Rad51-mediated DNA strand exchange promotes second ssDNA capture. EMBO J 25: 5539-5548.

Sung P. 1994. Catalysis of ATP-dependent homologous DNA pairing and strand exchange by yeast RAD51 protein. Science 265: 1241-1243.

Sung P. 1997. Yeast Rad55 and Rad57 proteins form a heterodimer that functions with replication protein A to promote DNA strand exchange by Rad51 recombinase. Genes Dev 11: 1111-1121.

Sung P, Robberson DL. 1995. DNA strand exchange mediated by a RAD51-ssDNA nucleoprotein filament with polarity opposite to that of RecA. Cell 82: 453-461.

Svendsen JM, Smogorzewska A, Sowa ME, O'Connell BC, Gygi SP, Elledge SJ, Harper JW. 2009. Mammalian BTBD12/SLX4 assembles a Holliday junction resolvase and is required for DNA repair. Cell 138: 63-77.

* Syeda AH, Hawkins M, McGlynn P. 2014. Recombination and replication. Cold Spring Harb Perspect Biol 6: a016550.

Symington LS. 2002. Role of RAD52 epistasis group genes in homologous recombination and double-strand break repair. Microbiol Mol Biol Rev 66: 630-670.
* Symington LS. 2014. End resection at double-strand breaks: Mechanism and regulation. Cold Spring Harb Perspect Biol 6: a016436.

Szankasi P, Smith GR. 1992. A DNA exonuclease induced during meiosis of Schizosaccharomyces pombe. J Biol Chem 267: 3014-3023.

* Székvölgyi L, Ohta K, Nicolas A. 2015. Initiation of meiotic homologous recombination: Flexibility, impact of histone modifications, and chromatin remodeling. Cold Spring Harb Perspect Biol 6: a016527.

Takata M, Sasaki MS, Tachiiri S, Fukushima T, Sonoda E, Schild D, Thompson LH, Takeda S. 2001. Chromosome instability and defective recombinational repair in knockout mutants of the five Rad51 paralogs. Mol Cell Biol 21: 2858-2866.

Tanaka K, Kagawa W, Kinebuchi T, Kurumizaka H, Miyagawa K. 2002. Human Rad54B is a double-stranded DNA-dependent ATPase and has biochemical properties different from its structural homolog in yeast, Tid1/ Rdh54. Nucleic Acids Res 30: 1346-1353.

Tao Y, Li X, Liu Y, Ruan J, Qi S, Niu L, Teng M. 2012. Structural analysis of Shu proteins reveals a DNA binding role essential for resisting damage. J Biol Chem 287: 20231-20239.

Taylor A, Smith GR. 1980. Unwinding and rewinding of DNA by the RecBC enzyme. Cell 22: 447-457.

Taylor AF, Smith GR. 2003. RecBCD enzyme is a DNA helicase with fast and slow motors of opposite polarity. Nature 423: 889-893.

Telander Muskavitch KM, Linn S. 1982. A unified mechanism for the nuclease and unwinding activities of the recBC enzyme of Escherichia coli. J Biol Chem 257: 2641-2648.

Thoms B, Wackernagel W. 1988. Suppression of the UVsensitive phenotype of Escherichia coli recF mutants by $\operatorname{rec} A(\mathrm{Srf})$ and $\operatorname{rec} A$ (Tif) mutations requires $\mathrm{recj}^{+} . \mathrm{J} \mathrm{Bac}-$ teriol 170: 3675-3681.

Tishkoff DX, Amin NS, Viars CS, Arden KC, Kolodner RD. 1998. Identification of a human gene encoding a homologue of Saccharomyces cerevisiae EXO1, an exonuclease implicated in mismatch repair and recombination. Cancer Res 58: 5027-5031.

Tomimatsu N, Mukherjee B, Deland K, Kurimasa A, Bolderson E, Khanna KK, Burma S. 2012. Exo1 plays a major role in DNA end resection in humans and influences double-strand break repair and damage signaling decisions. DNA Repair (Amst) 11: 441-448.

Tsai SP, Su GC, Lin SW, Chung CI, Xue X, Dunlop MH, Akamatsu Y, Jasin M, Sung P, Chi P. 2012. Rad51 presynaptic filament stabilization function of the mouse Swi5-Sfr1 heterodimeric complex. Nucleic Acids Res 40: 6558-6569.

Tsaneva IR, Illing G, Lloyd RG, West SC. 1992. Purification and properties of the RuvA and RuvB proteins of Escherichia coli. Mol Gen Genet 235: 1-10.

Umezu K, Kolodner RD. 1994. Protein interactions in genetic recombination in Escherichia coli. Interactions involving $\mathrm{RecO}$ and RecR overcome the inhibition of RecA by single-stranded DNA-binding protein. J Biol Chem 269: 30005-30013. 
Umezu K, Chi NW, Kolodner RD. 1993. Biochemical interaction of the Escherichia coli RecF, RecO, and RecR proteins with RecA protein and single-stranded DNA binding protein. Proc Natl Acad Sci 90: 3875-3879.

van der Heijden T, Modesti M, Hage S, Kanaar R, Wyman C, Dekker C. 2008. Homologous recombination in real time: DNA strand exchange by RecA. Mol Cell 30: 530 538.

van Loenhout MT, van der Heijden T, Kanaar R, Wyman C, Dekker C. 2009. Dynamics of RecA filaments on single-stranded DNA. Nucleic Acids Res 37: 40894099.

van Mameren J, Modesti M, Kanaar R, Wyman C, Peterman EJ, Wuite GJ. 2009. Counting RAD51 proteins disassembling from nucleoprotein filaments under tension. $\mathrm{Na}$ ture 457: 745-748.

Veaute X, Jeusset J, Soustelle C, Kowalczykowski SC, Le Cam E, Fabre F. 2003. The Srs2 helicase prevents recombination by disrupting Rad51 nucleoprotein filaments. $\mathrm{Na}$ ture 423: 309-312.

Veaute X, Delmas S, Selva M, Jeusset J, Le Cam E, Matic I, Fabre F, Petit MA. 2005. UvrD helicase, unlike Rep helicase, dismantles RecA nucleoprotein filaments in Escherichia coli. EMBO J 24: 180-189.

Viswanathan M, Lacirignola JJ, Hurley RL, Lovett ST. 2000 A novel mutational hotspot in a natural quasipalindrome in Escherichia coli. J Mol Biol 302: 553-564.

Voloshin ON, Ramirez BE, Bax A, Camerini-Otero RD. 2001. A model for the abrogation of the SOS response by an SOS protein: A negatively charged helix in DinI mimics DNA in its interaction with RecA. Genes Dev 15: 415-427.

Wang JC, Caron PR, Kim RA. 1990. The role of DNA topoisomerases in recombination and genome stability: A double-edged sword? Cell 62: 403-406.

West SC. 1997. Processing of recombination intermediates by the RuvABC proteins. Annu Rev Genet 31: $213-$ 244.

Whitby MC, Ryder L, Lloyd RG. 1993. Reverse branch migration of Holliday junctions by RecG protein: A new mechanism for resolution of intermediates in recombination and DNA repair. Cell 75: 341-350.

Wilson DM 3rd, Carney JP, Coleman MA, Adamson AW, Christensen M, Lamerdin JE. 1998. Hexl: A new human Rad2 nuclease family member with homology to yeast exonuclease 1. Nucleic Acids Res 26: 3762-3768.

Wold MS. 1997. Replication protein A: A heterotrimeric, single-stranded DNA-binding protein required for eukaryotic DNA metabolism. Annu Rev Biochem 66: 61-92.

Wright WD, Heyer WD. 2014. Rad54 functions as a heteroduplex DNA pump modulated by its DNA substrates and Rad51 during D loop formation. Mol Cell 53: 420432.

Wu L, Hickson ID. 2003. The Bloom's syndrome helicase suppresses crossing over during homologous recombination. Nature 426: 870-874.

Wu L, Hickson ID. 2006. DNA helicases required for homologous recombination and repair of damaged replication forks. Annu Rev Genet 40: 279-306.
Wu L, Davies SL, North PS, Goulaouic H, Riou JF, Turley H, Gatter KC, Hickson ID. 2000. The Bloom's syndrome gene product interacts with topoisomerase III. $J$ Biol Chem 275: 9636-9644.

Wu L, Davies SL, Levitt NC, Hickson ID. 2001. Potential role for the BLM helicase in recombinational repair via a conserved interaction with RAD51. J Biol Chem 276: 19375-19381.

Wu L, Bachrati CZ, Ou J, Xu C, Yin J, Chang M, Wang W, Li L, Brown GW, Hickson ID. 2006a. BLAP75/RMI1 promotes the BLM-dependent dissolution of homologous recombination intermediates. Proc Natl Acad Sci 103: 4068-4073.

Wu Y, Sugiyama T, Kowalczykowski SC. 2006b. DNA annealing mediated by Rad52 and Rad59 proteins. J Biol Chem 281: 15441-15449.

* Wyatt HDM, West SC. 2014. Holliday junction resolvases. Cold Spring Harb Perspect Biol 6: a023192.

Wyatt HDM, Sarbajna S, Matos J, West SC. 2013. Coordinated actions of SLX1-SLX4 and MUS81-EME1 for Holliday junction resolution in human cells. Mol Cell 52: $234-247$.

Xia B, Sheng Q, Nakanishi K, Ohashi A, Wu J, Christ N, Liu X, Jasin M, Couch FJ, Livingston DM. 2006. Control of BRCA2 cellular and clinical functions by a nuclear partner, PALB2. Mol Cell 22: 719-729.

Xu D, Guo R, Sobeck A, Bachrati CZ, Yang J, Enomoto T, Brown GW, Hoatlin ME, Hickson ID, Wang W. 2008. RMI, a new OB-fold complex essential for Bloom syndrome protein to maintain genome stability. Genes Dev 22: 2843-2855.

Yamada K, Miyata T, Tsuchiya D, Oyama T, Fujiwara Y, Ohnishi T, Iwasaki H, Shinagawa H, Ariyoshi M, Mayanagi K, et al. 2002. Crystal structure of the RuvARuvB complex: A structural basis for the Holliday junction migrating motor machinery. Mol Cell 10: 671-681.

Yang L, Handa N, Liu B, Dillingham MS, Wigley DB, Kowalczykowski SC. 2012. Alteration of $\chi$ recognition by RecBCD reveals a regulated molecular latch and suggests a channel-bypass mechanism for biological control. Proc Natl Acad Sci 109: 8907-8912.

Yeeles JT, Dillingham MS. 2010. The processing of doublestranded DNA breaks for recombinational repair by helicase-nuclease complexes. DNA Repair (Amst) 9: 276285.

Yeeles JT, Cammack R, Dillingham MS. 2009. An iron-sulfur cluster is essential for the binding of broken DNA by AddAB-type helicase-nucleases. J Biol Chem 284: 7746-7755.

Yin J, Sobeck A, Xu C, Meetei AR, Hoatlin M, Li L, Wang W. 2005. BLAP75, an essential component of Bloom's syndrome protein complexes that maintain genome integrity. EMBO J 24: 1465-1476.

Yonesaki T, Minagawa T. 1989. Synergistic action of three recombination gene products of bacteriophage T4, uvsX, uvsY, and gene 32 proteins. J Biol Chem 264: 7814-7820.

Yu X, Wu LC, Bowcock AM, Aronheim A, Baer R. 1998. The C-terminal (BRCT) domains of BRCA1 interact in vivo with CtIP, a protein implicated in the CtBP pathway 


\section{S.C. Kowalczykowski}

of transcriptional repression. J Biol Chem 273: 2538825392.

Yuan J, Chen J. 2011. The role of the human SWI5-MEI5 complex in homologous recombination repair. J Biol Chem 286: 9888-9893.

* Zelensky A, Kanaar R, Wyman C. 2014. Mediators of homologous DNA pairing. Cold Spring Harb Perspect Biol 6: a016451.

Zhang F, Fan Q, Ren K, Andreassen PR. 2009. PALB2 functionally connects the breast cancer susceptibility proteins BRCA1 and BRCA2. Mol Cancer Res 7: 1110-1118.

Zheng XF, Prakash R, Saro D, Longerich S, Niu H, Sung P. 2011. Processing of DNA structures via DNA unwinding and branch migration by the $S$. cerevisiae Mph1 protein. DNA Repair (Amst) 10: 1034-1043.

Zhu Z, Chung WH, Shim EY, Lee SE, Ira G. 2008. Sgs1 helicase and two nucleases Dna2 and Exo1 resect DNA double-strand break ends. Cell 134: 981-994.

* Zickler D, Kleckner N. 2015. Recombination, pairing, and synapsis of homologs during meiosis. Cold Spring Harb Perspect Biol 7: a016626.

Zimmermann M, de Lange T. 2014. 53BP1: Pro choice in DNA repair. Trends Cell Biol 24: 108-117.

Zimmermann M, Lottersberger F, Buonomo SB, Sfeir A, de Lange T. 2013. 53BP1 regulates DSB repair using Rif1 to control 5' end resection. Science 339: 700-704. 


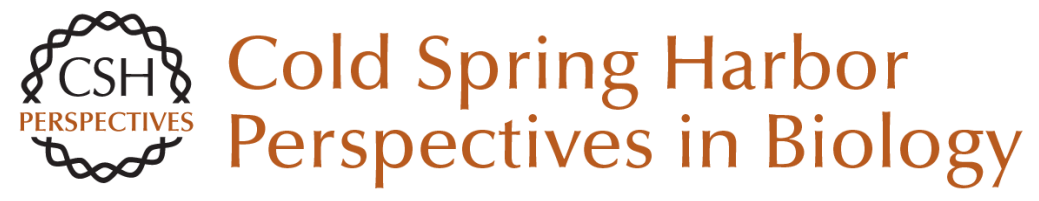

\section{An Overview of the Molecular Mechanisms of Recombinational DNA Repair}

Stephen C. Kowalczykowski

Cold Spring Harb Perspect Biol 2015; doi: 10.1101/cshperspect.a016410

\section{Subject Collection DNA Recombination}

Meiotic Recombination: The Essence of Heredity Neil Hunter

Regulation of Recombination and Genomic Maintenance Wolf-Dietrich Heyer

Initiation of Meiotic Homologous Recombination: Flexibility, Impact of Histone Modifications, and Chromatin Remodeling Lóránt Székvölgyi, Kunihiro Ohta and Alain Nicolas

Mechanism and Regulation of Meiotic

Recombination Initiation Isabel Lam and Scott Keeney

Homologous Recombination and Human Health: The Roles of BRCA1, BRCA2, and Associated Proteins Rohit Prakash, Yu Zhang, Weiran Feng, et al.

\section{Cell Biology of Mitotic Recombination} Michael Lisby and Rodney Rothstein

DNA-Pairing and Annealing Processes in Homologous Recombination and Homology-Directed Repair Scott W. Morrical
An Overview of the Molecular Mechanisms of

Recombinational DNA Repair

Stephen C. Kowalczykowski

Recombination, Pairing, and Synapsis of Homologs during Meiosis

Denise Zickler and Nancy Kleckner

DNA Strand Exchange and RecA Homologs in

Meiosis

M. Scott Brown and Douglas K. Bishop

Meiosis and Maternal Aging: Insights from

Aneuploid Oocytes and Trisomy Births Mary Herbert, Dimitrios Kalleas, Daniel Cooney, et al.

Mismatch Repair during Homologous and

Homeologous Recombination Maria Spies and Richard Fishel

Mechanisms of Gene Duplication and

Amplification

Andrew B. Reams and John R. Roth

The Role of Double-Strand Break Repair Pathways at Functional and Dysfunctional Telomeres Ylli Doksani and Titia de Lange

For additional articles in this collection, see http://cshperspectives.cshlp.org/cgi/collection/

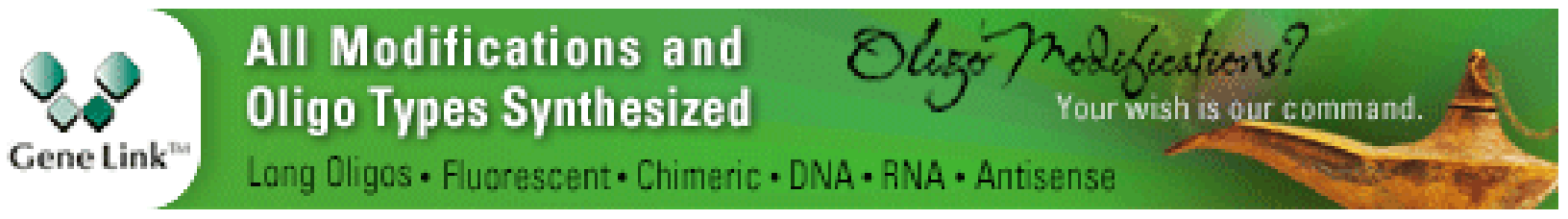




\section{Mediators of Homologous DNA Pairing}

Alex Zelensky, Roland Kanaar and Claire Wyman
Regulation of DNA Pairing in Homologous

Recombination

James M. Daley, William A. Gaines, YoungHo Kwon, et al.

For additional articles in this collection, see http://cshperspectives.cshlp.org/cgi/collection/

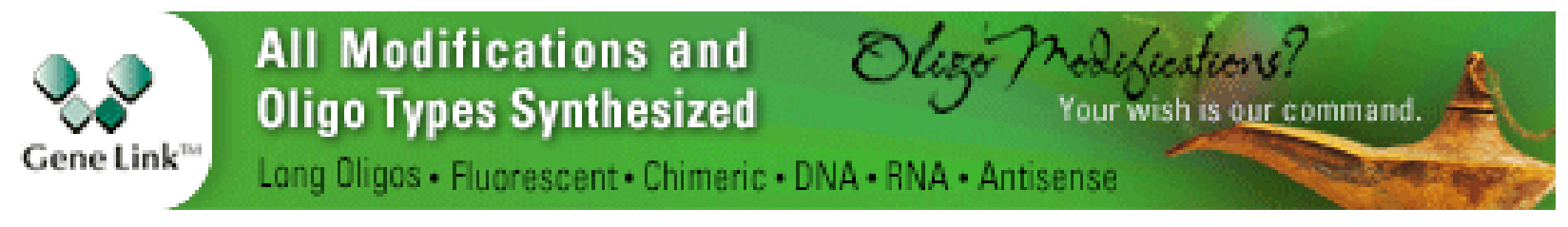

Copyright @ 2015 Cold Spring Harbor Laboratory Press; all rights reserved 